\title{
Bioactive Compounds and Quality of Extra Virgin Olive Oil
}

\author{
Cecilia Jimenez-Lopez ${ }^{1,2} \mathbb{D}$, Maria Carpena ${ }^{1} \mathbb{(}$, Catarina Lourenço-Lopes ${ }^{1} \mathbb{(}$, \\ Maria Gallardo-Gomez ${ }^{3}{ }^{(\mathbb{D}}$, Jose M. Lorenzo ${ }^{4}\left(\mathbb{D}\right.$, Francisco J. Barba ${ }^{5}{ }^{-}$, Miguel A. Prieto ${ }^{1, *(\mathbb{D}}$ and \\ Jesus Simal-Gandara ${ }^{1, *(\mathbb{D})}$
}

1 Nutrition and Bromatology Group, Department of Analytical and Food Chemistry, Faculty of Food Science and Technology, University of Vigo, Ourense Campus, E32004 Ourense, Spain;

cecilia.jimenez.lopez@uvigo.es (C.J.-L.); maria.carpena.rodriguez@uvigo.es (M.C.);

c.lopes@uvigo.es (C.L.-L.)

2 Centro de Investigação de Montanha (CIMO), Instituto Politécnico de Bragança, Campus de Santa Apolonia, 5300-253 Bragança, Portugal

3 CINBIO, Universidade de Vigo, Department of Biochemistry, Genetics and Immunology, Campus Universitario Lagoas Marcosende, 36310 Vigo, Spain; mgallardo@uvigo.es

4 Meat Technology Centre Foundation, 32900 San Cibrao das Viñas, Spain; jmlorenzo@ceteca.net

5 Nutrition and Food Science Area, Preventive Medicine and Public Health, Food Science, Toxicology and Forensic Medicine Department, Universitat de València, Faculty of Pharmacy, Avda, Vicent Andrés Estellés, s/n, Burjassot, 46100 València, Spain; francisco.barba@uv.es

* Correspondence: mprieto@uvigo.es (M.A.P.); jsimal@uvigo.es (J.S.-G.)

Received: 30 May 2020; Accepted: 24 July 2020; Published: 28 July 2020

\begin{abstract}
Background: Extra virgin olive oil (EVOO) is responsible for a large part of many health benefits associated to Mediterranean diet as it is a fundamental ingredient of this diet. The peculiarities of this golden, highly valued product are in part due to the requirements that must be met to achieve this title, namely, it has to be obtained using exclusively mechanical procedures, its free acidity cannot be greater than $0.8 \%$, it must not show sensory defects, and it has to possess a fruity taste. (2) Methods: All these characteristics are key factors to EVOO quality, thus the chemical composition of these many health-promoting compounds, such as unsaturated fatty acids (which are also the major compounds, especially oleic acid), as well as minor components such as tocopherols or phenolic compounds (which behave as natural antioxidants) must be preserved. (3) Results: Due to the presence of all these compounds, the daily consumption of EVOO entails health benefits such as cardioprotective, antioxidant, anti-inflammatory, anti-tumor properties or acting as regulator of the intestinal microbiota, among others. (4) Conclusions: Taking all together, conserving EVOO chemical composition is essential to preserve its properties, so it is worth to control certain factors during storage like exposure to light, temperature, oxygen presence or the chosen packaging material, to maintain its quality and extend its shelf-life until its consumption.
\end{abstract}

Keywords: extra virgin olive oil; chemical composition; bioactive substances; EVOO quality; applications

\section{Introduction}

Olea europaea L., commonly known as the olive tree, is a small tree species typically distributed by the Mediterranean countries [1]. Olive oil, its main derived product, has experienced an increase in its popularity due to its organoleptic characteristics and its associated beneficial health effects [2]. The olive tree is one of the species that was first cultivated. In fact, there are records for the first cultivated trees which date from 6000 years in Asia Minor regions according to the International 
Olive Council (IOC) [3]. Its origin is linked to Mediterranean civilizations and regions, characterized by soft and rainy winters and hot dry summers [4]. Although its industry uses large areas for the cultivation of trees, nowadays, its cultivation has been spread to regions of all continents (excluding Antarctica). Still, Mediterranean countries remain the main olive producers, led by Spain, Italy, and Greece. In consequence, the European Union (EU) is responsible for the $70 \%$ of the global olive production, generating a production value of 7000 million euros each year, becoming a key factor for the agro-industrial sector development and thus, a social and economic engine for the EU southern regions [5].

The French writer Georges Duhamel once wrote "There, where the olive tree gives up, is where the Mediterranean ends. The tree of light is the nature and culture of the Mediterranean" [6]. This statement corroborates the joining and simultaneous development of a culture-bound to olive products and particularly olive oil. So much, that olive oil is a crucial part of the commonly known as Mediterranean diet (MED). This diet consists of a balanced combination of low animal protein consumption with a high intake of fruits, vegetables and cereals and olive oil as the principal source of fat in many foods [3]. MED has been usually associated with a low incidence of cardiovascular diseases (CVD) risk in EU southern regions, which likewise, show higher life expectancy when compared to EU northern countries and the United States of America (USA) [7,8]. Several studies have been conducted to evaluate and prove MED as the main protective agent in the primary prevention of chronic diseases. Research has pointed out that the beneficial health effects of MED are attributed to a large extent to olive oil.

Some of those beneficial properties are gathered up in Figure 1. Its unique composition and biological properties are largely responsible for this association. Olive oil composition is mainly formed by triglycerides and a variety of several compounds in small quantities. Among the glyceride fraction, olive oil shows a high content of fatty acids and particularly, an elevated proportion of monounsaturated fatty acids (MUFA). Unsaturated acids are up to $85 \%$ of its composition, due to its high content in oleic acid (C18:1), which might range between $70-85 \%$ and other fatty acids as linoleic or palmitoleic acid. In the case of saturated fats, they entail around de $14 \%$ of oil composition, basically due to palmitic and stearic acids. Regarding minor compounds, they signify less than $2 \%$ of olive oil composition, and the best representatives of this group are phenolic compounds, although this minor group also includes some lipophilic compounds like $\alpha$-tocopherol (vitamin E). Likewise, there are several hydrophilic phenolic compounds, among which the simple phenol hydroxytyrosol and the secoiridoid oleuropein must be highlighted [1,8]. Besides, olive oil is also a source of pigments like carotenoids [3]. Phenolic compounds are known for their biological properties. In particular, these olive oil compounds have shown potential as antioxidant, anti-inflammatory and antimicrobial agents [9]. However, their concentration is related to different factors: olive varieties, environmental factors, time of harvest and extraction, and storage conditions [1]. To sum up, olive oil is considered as a superfood due to its health properties derived from its unique composition; this is, its lipid profile and its bioactive compounds content [10]. Moreover, its singular composition has attracted so much attention that olive oil has been studied as a source of these bioactive compounds but also their derived residues have shown high concentrations of these molecules and thus a great potential for industrial recovery and related applications, such as formulation of new high added value products [10]. 


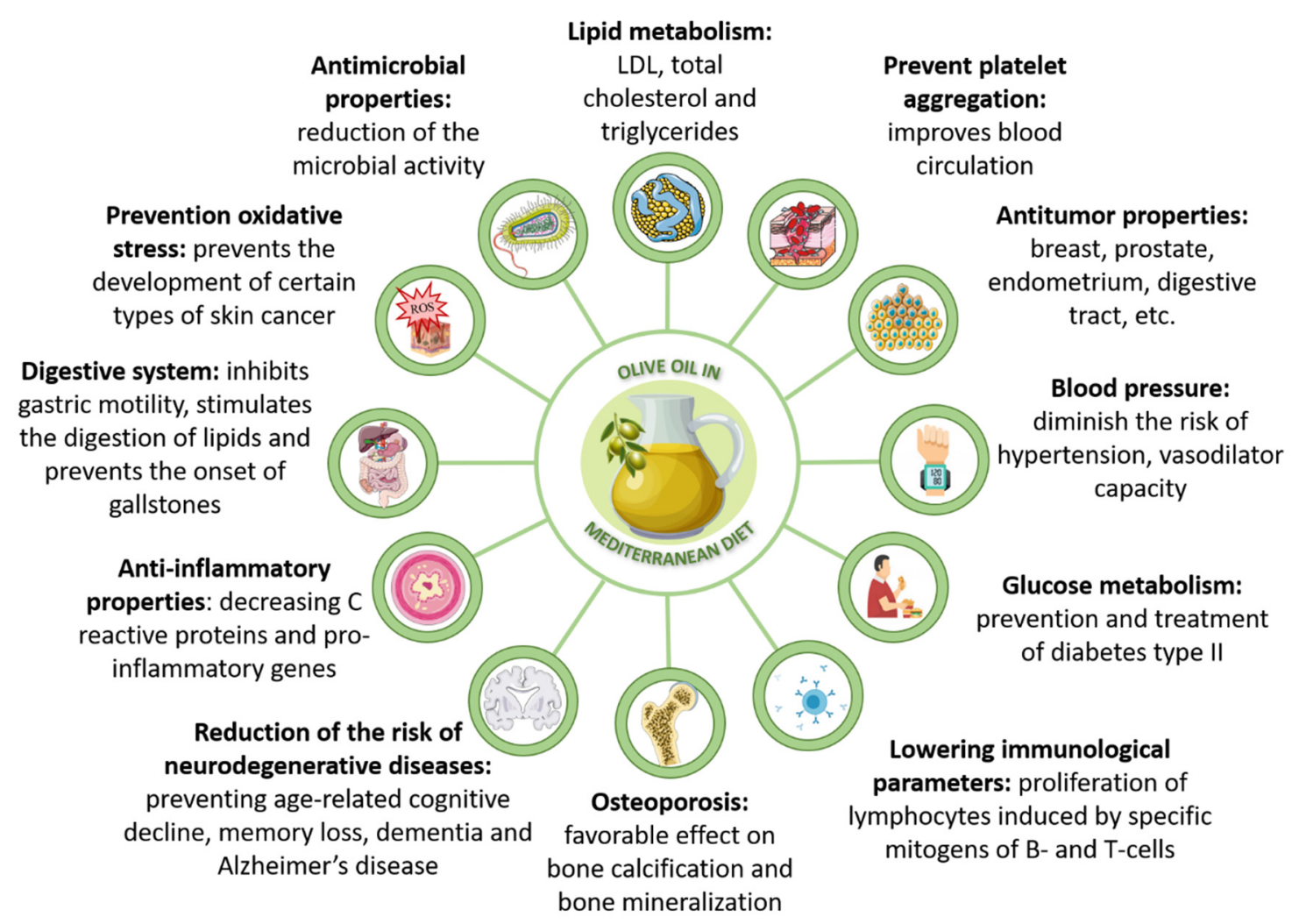

Figure 1. Scheme of the beneficial and healthy effects of the olive oil inclusion in the Mediterranean diet. Information adapted from [11,12].

Figure 2 shows a detailed procedure of the extraction of olive oil from Olea europaea L. of different varieties, whose extracting process follows a common line formed by different steps: collection, grading, washing, crushing, malaxing, separation and centrifugation, storage and packaging. This process is not aimed at improving oil quality; however, attention must be paid to its development to not cause a loss of quality $[13,14]$. Depending on the modifications of this process and the resultant organoleptic characteristics of the product, among others, the EU defines on the Article 118 of European Commission (EC) Regulation (EC) No 1234/2007 six main types of oils, which are delineated also by the IOC [15]. The specific attributes of each type of oil are shown in Table 1. Regarding all these groups, virgin olive oil (VOO) must be highlighted due to their organoleptic characteristics and beneficial properties. Among VOOs, the EU establishes three types of oils: extra virgin olive oil (EVOO), VOO, and lampante olive oil. Furthermore, IOC adds an extra subgroup called ordinary virgin oil. All VOOs are characterized for being obtained by mechanical processes (only washing, decantation, centrifugation and filtration) under specific thermal conditions which do not cause any alteration. Afterward, they are divided according to their acidity, which gives an idea of the content in free fatty acids based on the percentage of oleic acid. Lower acidity values guarantee a high-quality oil, showing it has been obtained from healthy olives and under ideal conditions. Moreover, they are submitted to sensory analysis to asses some requirements [16]. 


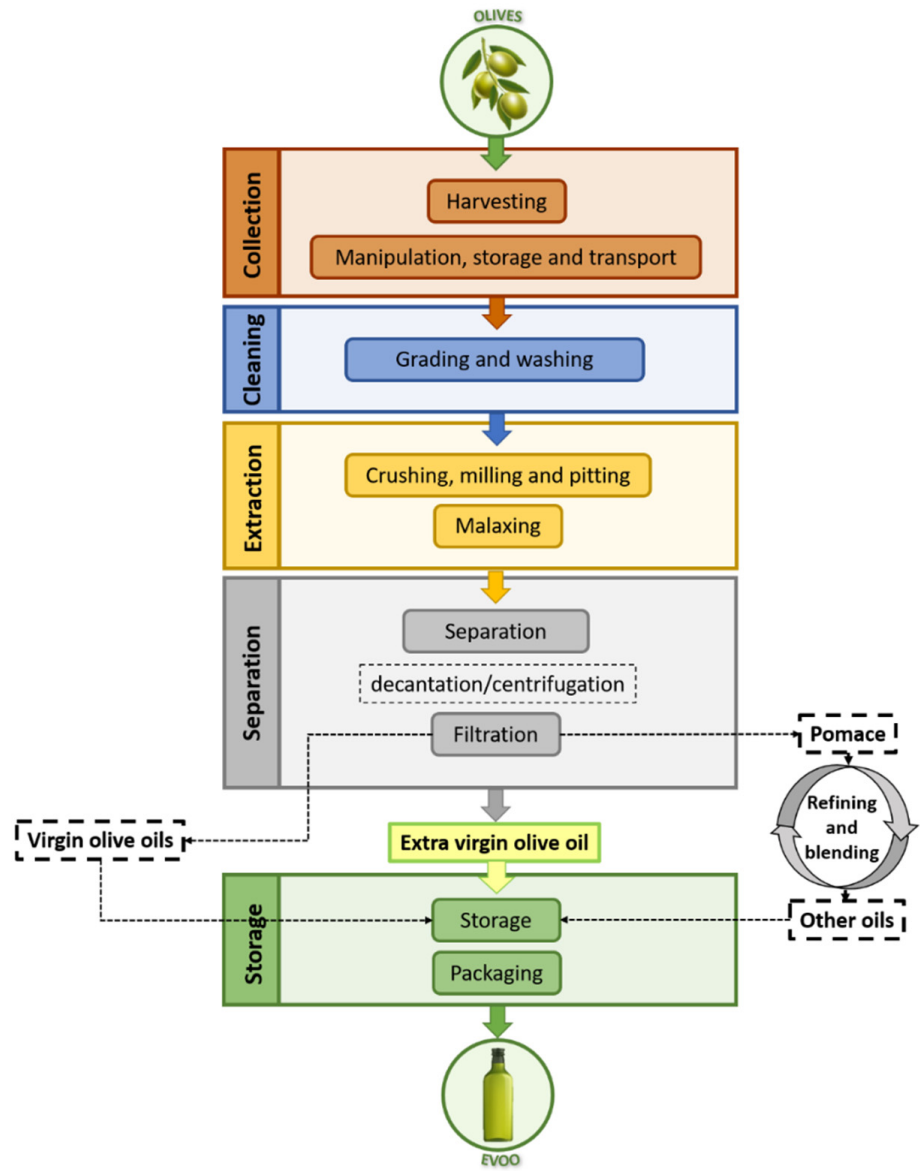

Figure 2. Summary of the oil extraction process focused on extra virgin olive oil (EVOO) production. The boxes with discontinuous outline refer to the obtainment of other type of oils. Modified from different schemes of $[10,17]$.

Table 1. Types of olive oils. Modified from EU Council Regulation (EC) No 1234/2007 [15].

\begin{tabular}{|c|c|c|c|}
\hline \multicolumn{2}{|c|}{ Type of Oil } & Characteristics & \multirow{2}{*}{$\begin{array}{l}\text { Free } \\
\text { Acidity } \\
0.8 \text { g per } \\
100 \mathrm{~g}\end{array}$} \\
\hline \multirow{3}{*}{ Virgin olive oils } & EVOO & \multirow{3}{*}{$\begin{array}{l}\text { They are characterized for being obtained by mechanical or other physical } \\
\text { processes under specific thermal conditions that do not cause alterations in } \\
\text { the oil and have not suffered any treatment other than washing, decantation, } \\
\text { centrifugation or filtration. Excluded are oils obtained using solvents or } \\
\text { adjuvants with chemical actions, by re-esterification process or any mixture } \\
\text { with oils of other types. }\end{array}$} & \\
\hline & $\begin{array}{l}\text { Virgin olive } \\
\text { oil }\end{array}$ & & $\begin{array}{l}\leq 2 \text { g per } \\
100 \mathrm{~g}\end{array}$ \\
\hline & $\begin{array}{l}\text { Lampante } \\
\text { olive oil }\end{array}$ & & $\begin{array}{l}>2 \mathrm{~g} \text { per } \\
100 \mathrm{~g}\end{array}$ \\
\hline \multicolumn{2}{|c|}{ Refined olive oil } & In this case, virgin olive oil is submitted to a refining process. & $\begin{array}{l}\leq 0.3 \mathrm{~g} \text { per } \\
100 \mathrm{~g}\end{array}$ \\
\hline \multicolumn{2}{|c|}{$\begin{array}{l}\text { Olive oil (composed of refined } \\
\text { olive oils and virgin olive oils) }\end{array}$} & $\begin{array}{l}\text { It is the result of the blending of the two previous oils: virgin olive oils (not } \\
\text { lampante oil) with refined olive oil. }\end{array}$ & $\begin{array}{l}\leq 1 \mathrm{~g} \text { per } \\
100 \mathrm{~g}\end{array}$ \\
\hline \multicolumn{2}{|c|}{ Crude olive pomace oil } & $\begin{array}{l}\text { This type refers to oil obtained from olive pomace by using solvents, physical } \\
\text { treatments or oil corresponding to lampante olive oil type, except for certain } \\
\text { specified characteristics. } \\
\text { As well as in the case of virgin olive oils, excluded are oils obtained by means } \\
\text { of re-esterification and mixtures with oils of other types. }\end{array}$ & \\
\hline \multicolumn{2}{|c|}{ Refined olive pomace oil } & This type is obtained from refining crude olive pomace oil. & $\begin{array}{l}\leq 0.3 \mathrm{~g} \text { per } \\
10 \mathrm{~g}\end{array}$ \\
\hline \multicolumn{2}{|c|}{ Olive pomace oil } & $\begin{array}{l}\text { It if the resultant oil from mixing refined olive pomace oil and virgin olive oil } \\
\text { different than lampante oil. }\end{array}$ & $\begin{array}{l}\leq 1 \mathrm{~g} \mathrm{per} \\
100 \mathrm{~g}\end{array}$ \\
\hline
\end{tabular}

NOTES: (1) The International Olive Council (IOC) establishes olive oil standards in terms of sensory analysis and chemical composition for each category. (2) In the case of Lampante oil, it is also referred as "virgin olive oil not fit for consumption" by the IOC and with a free acidity higher than $3.3 \mathrm{~g}$ per $100 \mathrm{~g}$. 
Particularly, EVOO is obtained directly from olives, that is, pure olive juice. It is considered the highest quality oil, and in general, it is characterized for having a low acidity, up to $0.8 \%$ and a sensory grade higher than 6.5 points, thus, having perfect aroma and flavor [3,10]. Regarding sensory aspects, EVOO must show a fruity note higher than 0 and, more importantly, a median of zero defects [18]. In addition, and to offer the most possible information to the consumer, these oils are usually labeled as intense, medium or light depending on their positive attributes [19]. However, sensory analysis is always more difficult to unify. On the other hand, EVOO is susceptible to different chemical alterations during its production. Hydrolytic and oxidative degradation are the main causes of undesirable product formation so that water plays an important role since lipases (naturally present at olive pulp or seeds) are active in an aqueous phase. Lipolytic reactions lead to the formation of free fatty acids, thus increasing the acidity of the oil. To avoid these reactions, the filtration step is of high importance, as well as paying attention to other factors such as avoiding microorganisms or mechanical crushing, among others. Moreover, water may affect the transformations of different phenolic compounds $[18,20]$. Regarding oxygen, EVOO must have a peroxide index $\left(\mathrm{mEqO}_{2} / \mathrm{kg}\right) \leq 20$. Oxygen is crucial for the lipoxygenase cascade reactions and its consequential positive sensory notes, but its excess can cause defects [20]. Moreover, EVOO must also show specific spectrophotometric values: absorption $\lambda=233 \mathrm{~nm}, \leq 2.50$ and $\lambda=270 \mathrm{~nm}, \leq 0.22$, which are quality and authenticity indicators, respectively [18]. Besides, contaminants (i.e., mycotoxins or pesticides, among others) are another crucial factor in avoiding associated risks [21]. Considering all the characteristics that EVOO is required to fulfill, quality control is a must. Both IOC and EC have approved different standards in matters of purity (oil composition) and quality (organoleptic profile, acidity, peroxide value, among others) as well as sensory analysis to ensure that alterations have not occurred during the process [10]. Additionally, another remarkable aspect is traceability. Traceability must be assured during all the obtaining process of EVOO, including the four basic steps (harvesting, milling, storage, and packaging batches) of the procedure to guarantee the identity of the product and its production chain. This approach also leads to the next step, this is certification, carried out by normalization and certification quality organisms in order to prove the rigorous process system employed at EVOO production [22,23].

Regarding its composition, EVOO is mainly composed of triglycerides (97-99\%) and minor compounds $(1-3 \%)$, which are the principal responsible for its biological properties and sensory attributes. It has a high content of MUFA (65-83\%), especially oleic acid, and some polyunsaturated fatty acids (PUFA) such as linoleic acid, which is considered a potent fatty acid on the reduction of low-density lipoprotein (LDL) cholesterol. This lipid profile and also high $\omega 6 / \omega 3$ ratio have been linked to protective effects on coronary, autoimmune and inflammatory disorders but also as anti-thrombotic and regulators of blood pressure [24-26]. Concerning bioactive compounds, their main representatives are the same of oil in general, namely phenolic compounds such as hydroxytyrosol and derivatives (oleuropein and tyrosol), tocopherols but also other compounds as hydrocarbons (i.e., squalene) or pigments like provitamin A compounds $[3,26]$. However, it must be mentioned that some of these compounds such as squalene might be lost during refinery, so they can only be found on this type of oil [25].

As mentioned, all these bioactive compounds are known for their biological properties and positive effects on human health. EVOO inclusion in the diet and its bioactive molecules have been studied to identify its effects. EVOO is known for having a high content of antioxidant compounds with protective properties against free radicals. Therefore, it has been pointed out that its high consumption is related to a generally low risk of suffering colon, breast or skin cancer as well as beneficial effects on aging and coronary diseases [1]. It has also been proposed as a preventing tool of Alzheimer's and other neurodegenerative diseases [3], as anti-inflammatory [7] and also as immune-stimulating [24]. Another study proved that rats fed with EVOO in substitution of lipids and complemented with physical exercise, could avert cartilage diseases as osteoarthritis [9]. Additionally, EVOO consumption has shown positive effects on gut microbiota [27]. Some studies have researched the bioavailability of phenolic compounds of EVOO and found that $55-60 \%$ of them can be absorbed, most of them at 
small intestine [11]. Moreover, their different compounds have shown other beneficial properties like antimicrobial, antitumor or protective agents against cellular damage [26,28]. More specific studies have also related EVOO treatment with positive gene regulation and with micro ribonucleic acid (miRNA) modulation of target genes associated with synaptic plasticity as well as to motor and cognitive behavior [29]. There are multiple bibliographic references directed towards proving all these promoting effects. Nevertheless, a specific study must be highlighted, the PREDIMED trial (prevention through MED, in Spanish). This is one of the largest nutritional studies ever conducted in Spain, which evaluated the effects on primary prevention of CVD when following a MED supplemented by EVOO or nuts mix [30]. This project groups together different studies, which have brought to light several positive consequences: reduction of CVD risk, reduction of C-reactive protein, reduction of atrial fibrillation, prevention of diabetes and metabolic syndrome, reduction of diastolic blood pressure, higher protection against breast cancer or lower prevalence of non-alcoholic fatty acid liver disease [25,31-33]. However, more epidemiologic studies and controlled trials are necessary to better validate and understand the beneficial effects of EVOO consumption. At last, it is worth mentioning that new disciplines (encompassed as nutrigenomics) are also working on new approaches for evaluating the health-promoting effects, characterizing new markers, and understanding their action mechanisms [29,34].

Regarding all the presented information, this article aims to review the current knowledge about the unique EVOO composition and its related bioactivities. Therefore, a revision focused on its beneficial and health-promoting properties, its chemical composition as well as some quality parameters is presented. To achieve this purpose, a systematic search in several databases was carried out based on the topic described, all in all, $\sim 5000$ documents have been published. Most of the publications correspond to research articles and book chapters, $56.3 \%$ and $15.6 \%$, respectively, followed by reviews $(12.5 \%)$. Among them, bibliographic references were chosen according to their concordance with the covered topics. The extensive information compiled was further classified into the different sections presented in this review. After analyzing the considerable amount of data available on this field, it can be said that EVOO is a current topic; although it has been known and used for centuries, it is still under study, which means EVOO has potential properties and/or applications yet to be discovered.

\section{Main Components of EVOO}

Virgin olive oils are oils obtained from the fruit of the olive tree (Olea europaea L.) solely by mechanical or other physical means under conditions, particularly thermal conditions, that do not lead to alterations in the oil, and which have not undergone any treatment other than washing, decantation, centrifugation and filtration [35]. The use of said physical techniques allows the preservation of many compounds that make EVOO one of a kind among plant oils. Its uniqueness is due to the abundance of fatty acids, PUFA and MUFA but also the occurrence of many bioactive molecules, like hydrophilic phenols, phytosterols, tocopherols and carotenes that provide several functional properties as well as a long storage time due to their high oxidative stability [36-38]. Other vegetable oils, like palm oil, are rich in saturated fats, which are more stable during the cooking or frying processes than the unsaturated ones, avoiding degradation to toxic compounds, but they do not have beneficial properties for the human health as the unsaturated one. On the other hand, sunflower oil is rich in unsaturated fats, especially in linoleic and oleic acids that enhance its healthy properties but decrease its thermal stability [39]. EVOO has a good PUFA:MUFA balance, which confers it stability properties against oxidative thermal degradation, particularly regarding the formation of volatile aldehydes, so EVOO is a proper and recommendable oil to use in food frying [40]. This relation between PUFA and MUFA and the low content of saturated fats also makes EVOO one of the healthiest vegetable oils to be consumed raw because it helps reduce LDL cholesterol levels in the human body [41].

The composition of EVOO is a result of several factors like genotypic potential, environmental factors, fruit ripening, harvest time, agricultural factors (irrigation, sunlight, orchard management) and also technological factors like the method applied for oil extraction or the storage conditions [42]. 
The concentration of the minor and major fruit components changes and depends on all those variables. Apart from that, the olives ripening process lasts a few months in which the atmospheric, environmental and agricultural conditions play a very important role despite the strict genetic control that can be applied $[43,44]$. During the maturation and ripening process, the photosynthetic activity decreases as the oil content in the fruits increases [45]. In the first stage of ripening, denominated green stage, the ripe fruits have already acquired their final size, so the maturation proceeds, and the chlorophylls in the skin are slowly swapped by anthocyanins, turning the olives from green to dark violet or purple until the end of the ripping process. These changes in color define the spotted, purple and black stages $[43,46]$. Olives have the highest phenolic compound content at the phase between green and darker skin, and therefore, the degree of maturation is an important factor to define the right harvest time that will originate the best quality olive oil [47]. Figure 3 shows a summary of representative chemical structures of some relevant compounds present in EVOO.
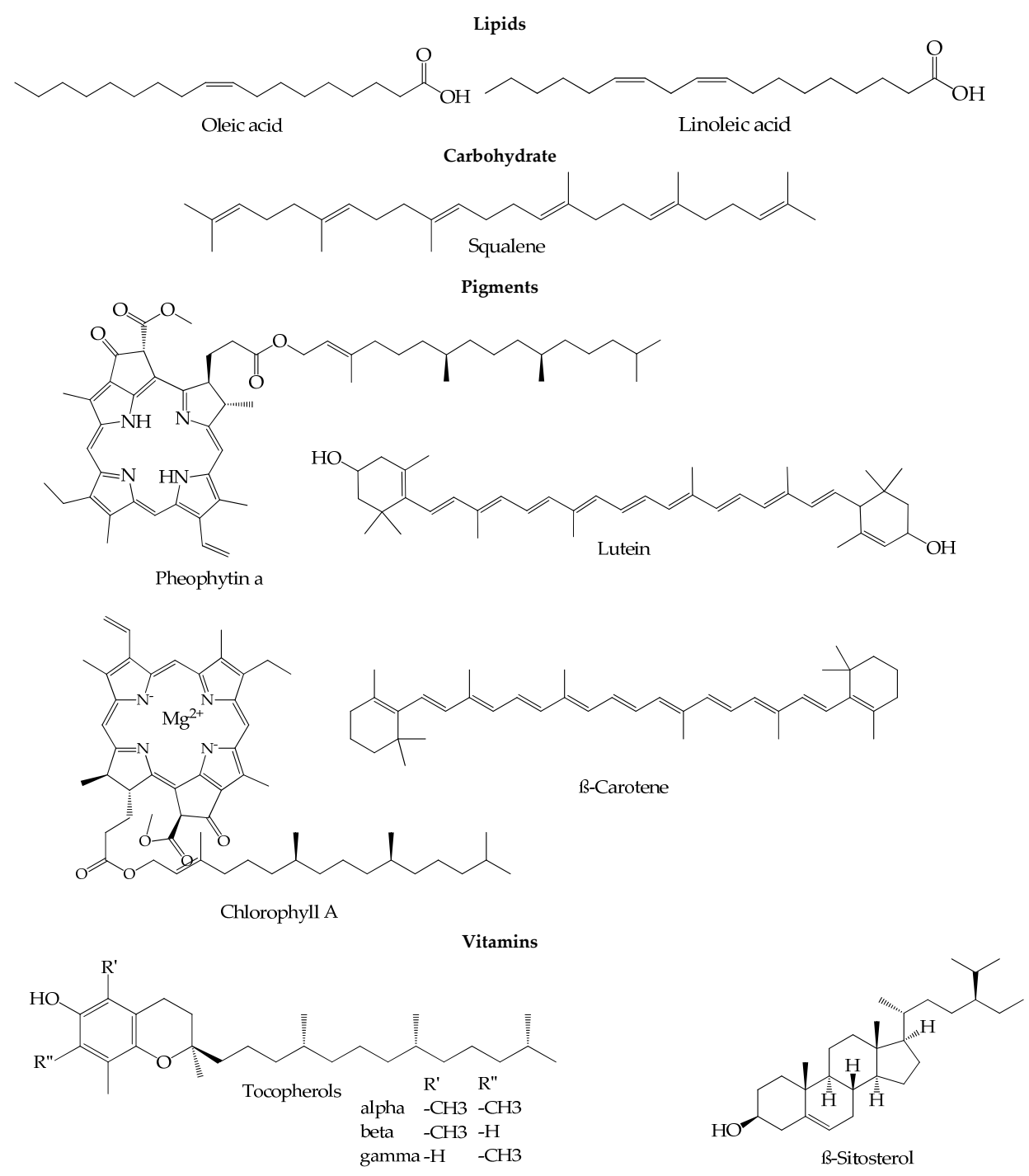

Figure 3. Representative chemical structures of some relevant compounds present in EVOO.

\subsection{Primary Metabolites}

\subsubsection{Lipids}

Lipids are one of the principal sources of energy for all living beings and additionally, they are also involved in many physiological functions, as their role as a structural component of cell membranes, 
nervous system, the production of hormones, brain development and also on the promotion of liposoluble vitamins absorption.

EVOO is widely used in the human diet, especially in the MED and has been long renowned for its many health-promoting properties. Its consumption is associated with reduced risk of several chronic illnesses, like diabetes, hypertension, obesity and CVD [48,49]. These health properties are related to the presence of bioactive compounds like phenolic compounds but also with the high content in MUFA. Olive oil has a high content in oleic acid transforming it into a healthy fat, especially when compared with other vegetable oils [40]. This lipid can decrease the risk of CVD due to its effects on the lipids present in the blood vessels [50]. According to available data, there is $65.2-80.8 \%$ of MUFA in the lipidic fraction of olive oil [51]. Other fatty acids found in the total fatty acids composition of olive oils are palmitic acid, palmitoleic acid, stearic acid, linoleic acid, $\alpha$-linolenic acid, and other minor ones that are listed in Table 2.

Triacylglycerols constitute a big part of the edible oil and a high percentage of the saponifiable fraction is constituted by MUFA [27]. The principal triacylglycerol detected in olive oil is oleic-oleic-oleic (OOO), representing about half of the total triacylglycerol portion found in EVOO. Other triacyclglycerols also present are palmitic-oleic-oleic (POO), oleic-oleic-linoleic (OOL), palmitic-oleic-linoleic (POL) and stearic-oleic-oleic (SOO) [43,52]. Diacylglycerols and monoacylglycerols have been identified in $\mathrm{VOO}$ at concentrations of $1-2.8 \%$ and 0.25 , respectively [53].

Table 2. Major EVOO components.

\begin{tabular}{|c|c|c|c|}
\hline \multicolumn{2}{|c|}{ Component } & Concentration & References \\
\hline \multicolumn{4}{|c|}{ Lipids } \\
\hline \multicolumn{4}{|c|}{ Fatty acids (\%) } \\
\hline Myristic acid & $\mathrm{C} 14: 0$ & 0.05 & [53] \\
\hline Palmitic acid & $\mathrm{C} 16: 0$ & $9.4-19.5$ & {$[51,54]$} \\
\hline Palmitoleic acid & $\mathrm{C} 16: 1$ & $0.6-3.2$ & {$[51,54]$} \\
\hline Heptadecanoic acid & $\mathrm{C} 17: 0$ & $0.07-0.13$ & {$[51]$} \\
\hline Heptadecenoic acid & $\mathrm{C} 17: 1$ & $0.17-0.24$ & [51] \\
\hline Stearic acid & $\mathrm{C} 18: 0$ & $1.4-3.0$ & {$[51,54]$} \\
\hline Oleic acid & $\mathrm{C} 18: 1$ & $63.1-79.7$ & {$[51,54]$} \\
\hline Linoleic acid & $\mathrm{C} 18: 2$ & $6.6-14.8$ & {$[51,54]$} \\
\hline$\alpha$-Linolenic acid & $\mathrm{C} 18: 3$ & $0.46-0.69$ & {$[51,54]$} \\
\hline Arachidic acid & $\mathrm{C} 20: 0$ & $0.3-0.4$ & {$[51,54]$} \\
\hline Eicosenoic acid & $\mathrm{C} 20: 1$ & $0.2-0.3$ & {$[51,54]$} \\
\hline Docosanoic acid & $\mathrm{C} 22: 0$ & $0.09-0.12$ & {$[51,54]$} \\
\hline Lignoceric acid & $\mathrm{C} 24: 0$ & $0.04-0.05$ & {$[51]$} \\
\hline \multicolumn{2}{|c|}{ MUFA } & $65.2-80.8$ & [51] \\
\hline \multicolumn{2}{|c|}{ PUFA } & $7.0-15.5$ & [51] \\
\hline \multicolumn{4}{|c|}{ Other lipids } \\
\hline \multicolumn{2}{|c|}{ Diacylglycerols (\%) } & $1-2.8$ & [53] \\
\hline \multicolumn{2}{|c|}{ Monoacylglycerols (\%) } & 0.25 & [53] \\
\hline \multicolumn{2}{|c|}{ Total sterol content $(\mathrm{mg} / \mathrm{kg})$} & $1000-3040$ & {$[43,55]$} \\
\hline \multicolumn{4}{|c|}{ Tocopherols (mg/kg) } \\
\hline \multirow{3}{*}{\multicolumn{2}{|c|}{$\begin{array}{l}\alpha \text { - Tocopherol } \\
\beta \text { - Tocopherol } \\
\gamma \text { - Tocopherol }\end{array}$}} & $10.2-208$ & {$[51,54,56]$} \\
\hline & & $0.75-1.05$ & [51] \\
\hline & & $0.7-2.1$ & [51] \\
\hline \multicolumn{4}{|c|}{ Carbohydrates (mg/kg) } \\
\hline Squa & & $200-8260$ & {$[43,54,56,57]$} \\
\hline \multicolumn{4}{|c|}{ Pigments (mg/kg) } \\
\hline Total chlorop & $\mathrm{kg})$ & $0.15-61.96$ & {$[51,58]$} \\
\hline Pheophytin & & $0.08-0.49$ & {$[56]$} \\
\hline Total caroten & & $0.53-31.51$ & {$[51,54,58]$} \\
\hline$\beta$-caroten & & $0.15-0.67$ & [56] \\
\hline Lutein & & $0.65-3.60$ & [56] \\
\hline \multicolumn{4}{|c|}{ Other Compounds } \\
\hline Total phenolic con & $(\mathrm{mg} / \mathrm{kg})$ & $213-450$ & [54] \\
\hline Triterpene dialcohol & tal sterols) & $0.9-2.8$ & [55] \\
\hline$\beta$-sitosterc & & $530.2-2638.6$ & [56] \\
\hline
\end{tabular}


Four classes of sterols also take place in olive oil and are commonly used to check its genuineness because their presence is linked to the quality of the oil. These four classes are common sterols (4-Desmethylsterols), $4 \alpha$-Methylsterols, triterpene alcohols (4, 4-Dimethylsterols) and triterpene dialcohols [43]. Common sterols in EVOO are present in both free and esterified forms [59]. The leading components of this sterol fraction are campesterol, $\beta$-Sitosterol and $\Delta 5$-Avenasterol $[60,61]$, and in smaller amounts, it is also possible to find stigmasterol, cholesterol, cholesterol, brassicasterol, sitostanol, ergosterol, campestanol, $\Delta 7$-Cholestenol, $\Delta 7$-Avenasterol, $\Delta 7$-Stigmasterol, $\Delta 7$-Campesterol, $\Delta 5,24$-Stigmastadienol, $\Delta 5,23$-Stigmastadienol, $\Delta 7,24$-Ergostadienol, $\Delta 7,22$-Ergostadienol, 22,23-Dihydrobrassicasterol and 24-Methylene-cholesterol [62,63]. The total sterol content of EVOO varies between 1000 and $2000 \mathrm{mg} / \mathrm{kg}$, being the first value the inferior limit set by the EU Commission [43]. $\beta$-Sitosterol is the main compound in the sterol fraction with values between $75 \%$ and $90 \%$ of the total sterol fraction, while $\Delta 5$-Avenasterol has values between $5 \%$ and $20 \%$ [62]. Crop year, cultivar, ripeness of the fruit, storage time of the olives before oil extraction and geographic influences all contribute to sterol composition of the final EVOO obtained [64-66]. At the same time, storage time and conditions of the final product are also factors that can originate several important changes particularly in the concentrations of each individual sterol [43]. 4-Monomethylsterols are present in smaller amounts and signify part of sterol biosynthesis as intermediates. They can be found in their free and esterified forms [67]. The most common are gramisterol, obtusifoliol, cycloeucalenol and citrostadienol [60,62], and their concentrations vary between 50 and $360 \mathrm{mg} / \mathrm{kg}$ of oil $[60,68]$. Triterpene alcohols, also identified as 4,4-Dimethylsterol, are a very complex fraction that can be in free and esterified form, and whose main compounds are butyrospermol, $\beta$-Amyrin, cycloartenol and 24-Methylenecycloartanol. In smaller amounts or trace quantities, cyclosadol, cyclobranol, dammaradienol, germanicol, 24-Tirucalladienol, 24-Methylene-24-Dihydroparkeol, $\alpha$-Amyrin, taraxerol, 7, parkeol and tirucallol can also be found [62]. Total triterpene alcohol levels range from values of 350 to $1500 \mathrm{mg} / \mathrm{kg}[68,69]$. Lastly, among the triterpene dialcohols class, erythrodiol ( $5 \alpha$-olean-12-ene-3 $\beta$, 28-diol, homo-olestranol) in free and esterified form and uvaol ( $\Delta 12$-Ursen-3 $\beta, 28$-diol) are the major triterpene dialcohols found in EVOO [70], and their presence is mainly affected by cultivation characteristics [68]. EVOO contains levels of total erythrodiol from 19 to $69 \mathrm{mg} / \mathrm{kg}$ of oil, and the free form is inferior to $50 \mathrm{mg} / \mathrm{kg}[59,68]$.

\subsubsection{Tocopherols}

Three isoforms of tocopherols are present in EVOO: $\alpha$-, $\beta$ - and $\gamma$-tocopherol. $\alpha$-Tocopherol can be found in its free form and represents more than $90 \%$ of the identified section with ranges from 206.5 to $270.9 \mathrm{mg} / \mathrm{kg}$ of oil to 191.5 to $292.7 \mathrm{mg} / \mathrm{kg}$ of oil, values that fluctuate with variables as the year of harvest and spacing between olive trees [71]. Both, the distance between plants and the crop year influenced statistically tocopherols amount [43,71]. Besides, the high levels of this type of tocopherol may be linked to the high levels of chlorophyll pigments and the simultaneous necessity for singlet oxygen deactivation [72].

Lower quantities of $\beta$-Tocopherol $(\sim 10 \mathrm{mg} / \mathrm{kg}), \gamma$-Tocopherol $(\sim 20 \mathrm{mg} / \mathrm{kg})$ and $\delta$-Tocopherol $(\sim 10 \mathrm{mg} / \mathrm{kg})$ can also be found on EVOO. The total tocopherol concentration seems to decrease in the ripping of the fruits, and the refining or the hydrogenation process causes their degradation, so they are only found in the EVOO and VOO [73].

\subsubsection{Carbohydrates}

There are two hydrocarbons mainly present in olive oil, 2,6,10,15,19,23-Hexamethyl-2,6,10,14,18,22Tetracosahexaene also known as squalene and $\beta$-Carotene, which will be addressed in the pigments section of this review. Squalene is the last metabolite synthesized before the sterol ring formation. Some of the beneficial health effects of olive oil are partially linked with the presence of squalene, and it has also demonstrated antitumoral effects against certain types of cancer [74,75]. This compound constitutes more than $90 \%$ of the hydrocarbon fraction and is the most abundant compound in the unsaponifiable matter, with concentrations ranging from 200 to $7500 \mathrm{mg} / \mathrm{kg}$ oil [57]. In a different 
study, squalene was reported in even higher concentrations, up to $12,000 \mathrm{mg} / \mathrm{kg}$ oil. Squalene content depends on several variables like the type of olive cultivation and the oil extraction technique applied, and it decreases largely during the refining process so it is present in larger quantities in EVOO and VOO [76].

The remaining fraction of carbohydrates in EVOO is composed of triterpene and diterpene, isoprenoid polyolefins, hydrocarbons and n-paraffins $[43,76]$.

\subsection{Secondary Metabolites}

\subsubsection{Phenolic Compounds}

The principal group of antioxidants in EVOO are hydrophilic phenols, and these compounds are extremely relevant when it comes to determining the quality of the oil regarding their sensory characteristics, like bitterness, pungency and stability [38,77], as well as determining the organoleptic characteristics of aroma and flavor of each EVOO [53]. The oxidative stability of EVOO depends not only on the olive variety and quality but also on the harvesting time; cultivation area; the degree of unsaturation and the levels of antioxidants present from tocopherols, hydrophilic phenols and carotenes. Besides, factors like oil extraction system and storage conditions also influence its conservation [78].

The correlation of the phenolic content of olive oil and oxidative stability was studied showing that these two are interconnected [79]. Furthermore, EVOO phenolic compounds provide benefits for human health in the prevention of several chronic diseases [80,81]. Various studies indicate that EVOO phenolic compounds have antioxidant, anti-inflammatory, antimicrobial and antitumoral activities, and they can also modulate gene expression to protect proteins that take part in the cellular mechanisms involved in the inflammation process, the oxidative stress resistance and in lipid metabolism [82,83]. Therefore, the major antioxidant substances found in EVOO are polar phenolic compounds that can be present in free, bound or esterified forms [43], and usually, its total phenolic content ranges between 50 and $1000 \mathrm{mg} / \mathrm{kg}$ [84], being more common in concentrations between 100 and $300 \mathrm{mg} / \mathrm{kg}$ [43]. Likewise, each EVOO has a different phenolic profile, content and composition due to the differences discussed above [78].

Phenolic compounds have been largely reported in EVOO composition, with more than 30 different compounds identified $[47,85]$, being the major phenolic acids present in EVOO hydroxybenzoic, $p$-Coumaric, ferulic, gallic, syringic, vanillic, caffeic, $o$-coumaric and sinapic acids [53]. Other types of polyphenols that can also be found in EVOO are flavonoids, lignans, hydroxy-isocromans, secoiridoids and phenolic alcohols. The major flavonoids found in EVOO are luteolin, apigenin and many of their derivates $[86,87]$, whereas the main lignans present are $(+)$-pinoresinol and (+)-1-Acetoxypinoresinol [88], being the usual lignan content in EVOO between 1 and $100 \mathrm{mg} / \mathrm{kg}$ [89].

Secoiridoids are rare phenolic compounds present in plant species, nevertheless, they are found in abundance in Oleaceae species, particularly in O. europaea leaves and fruits. However, they are insoluble in oil and therefore only a small percentage of these compounds ends up in the final EVOO after the mechanic extraction process. Nevertheless, they are one of the most important micronutrients on EVOO for their sensorial and heath properties [38,80]. The most common secoiridoids are demethyloleuropein, oleuropein, ligstroside and their aglycones, the last ones accounting for approximately $90 \%$ of the phenolic compounds in EVOO [90]. Secoiridoids are hydrolyzed through crushing and malaxation by enzymatic reactions catalyzed by endogenous b-glucosidases yielding secoiridoid aglycons [91]. The bitterness of olive oil is due to the secoiridoids present, especially the dialdehydic form of oleuropein aglycone [92].

Isochromans are only found at low concentration in EVOO, and the two mainly found are 1-Phenyl6,7-dihydroxy-isochroman and 1-(3'Methoxy-4'-hydroxy)phenyl-6,7-dihydroxy-isochroman [93]. The concentration of these compounds increases during the extraction process because of the hydrolytic process that originates carbonyl compounds and hydroxytyrosol, which are isocromans derivatives [88]. Finally, the principal phenolic alcohols found in EVOO are tyrosol (p-Hydroxyphenyl ethanol) and 
hydroxytyrosol (2-[3,4-Dihydroxyphenyl] ethanol). These are present in small concentrations in fresh olive oil but tend to increase along the storage process because of the hydrolysis of olive oil secoiridoids [94].

\subsubsection{Pigments}

The lipophilic carotenoid and chlorophyll pigments occurring in olive oil are responsible for its characteristic color [95]. The coloration of EVOO is greener in the presence of green olives that have higher chlorophyll content whereas using mature olives with higher carotenoid content we obtain a more yellowish oil, so the final color is a result of the proportions of these pigments [96]. EVOO has a large variety of carotenoids and chlorophylls, from $\beta$-Carotene, violaxanthin, neoxanthin, lutein and other xanthophylls to chlorophyll $a$ and $b$, pheophytin $a$ and $b$ and other minor derivatives $[97,98]$. These pigments can be found in amounts up to $100 \mathrm{ppm}$ of total carotenoids and major pigments like pheophytin up to $25 \mathrm{ppm}, \beta$-carotene up to $15 \mathrm{ppm}$ and lutein up to $10 \mathrm{ppm}$ [96], although these values depend on various factors. The final concentration of each pigment in the final EVOO relies on the physicochemical characteristics of the fruit, the geographic origin, climate and irrigation conditions and the mechanic extraction process used. Storage conditions and final packaging also play a role in pigment concentration and type $[96,99,100]$.

Quality and adulteration of EVOO are sometimes analyzed through the measuring of pigment compounds because they are correlated with EVOO nutritional value, freshness and antioxidant properties [99,101]. In addition, pigments can also be used for the authentication of EVOO, by measuring the chlorophyll and carotenoid pigments of EVOO and comparing them through a quality index, in which the total chlorophylls to total carotenoids ratio must be around 1 and the ratio of minor carotenoids to lutein must be around 0.5 , to declare it an authentic olive oil [102]. These parameters are valid for any olive oil regardless of the studied variety. Furthermore, other pigments like violaxanthin, lutein and total pigment content can be useful as a tool to identify a monovarietal EVOO [102]. Chlorophylls, carotenoids and other minor pigments like lutein and violaxanthin can be stable for more than one year in storage regardless of the degree of ripeness and variety of the olives used to produce that oil [103].

The degradation of chlorophylls occurs as a consequence of a pheophytinization reaction that starts from the malaxation step during the extraction of the EVOO and increases throughout storage time [104]. During that process, the chlorophylls naturally present ( $a$ and $b$ ) are slowly but irreversibly converted into pheophytins $\mathrm{a}$ and $\mathrm{b}$, where the central $\mathrm{Mg}^{+2}$ ion of the porphyrin ring is exchanged with two hydrogen atoms making the molecules more stable. These eventually turn to pyropheophytins by the removal of the carboxymethyl group, which are the ultimate products of chlorophyll degradation [105].

\section{Biological Properties of EVOO}

The Seven Country Study conducted in the middle of the 20th century first demonstrated the cardioprotective capacities and health benefits of MED [106], olive oil being the hallmark of this dietary pattern. Since then, plenty of observational and epidemiological studies have demonstrated the health-promoting effects of consuming olive oil.

Many health benefits of following a MED enriched in EVOO have been reported by the PREDIMED trial [107], such as protection against CVD [30] or oxidative damage [108,109] and prevention of breast cancer [110] and type 2 diabetes mellitus [111]. Many other randomized controlled trials, prospective study cohorts and meta-analysis, supported by in vitro experiments, indicate that EVOO possesses interesting biological activities and pharmaceutical-nutritional properties (Table 3) that exert a beneficial health impact that stands out over other fats and oils. Nevertheless, many attributes of EVOO are also related to the MED, the context in which its beneficial effects have been mainly evaluated. 
Table 3. Main bioactivities associated with EVOO consumption.

\begin{tabular}{|c|c|c|c|}
\hline Bioactivity & Studies Description & Main Results & Ref \\
\hline \multirow{5}{*}{ Cardioprotection } & $\begin{array}{c}\text { RCT, PREDIMED ( } n=7447 \text { participants at } \\
\text { high CVD risk) }\end{array}$ & $\begin{array}{c}\text { Following a MED enriched with EVOO } \\
\text { decreases CVD risk by } 30 \%\end{array}$ & {$[30,107]$} \\
\hline & $\begin{array}{l}\text { PREDIMED observational study } \\
\qquad(n=7216 \text { participants })\end{array}$ & $\begin{array}{l}\text { For each } 10 \mathrm{~g} \text { EVOO/day intake, CVD risk } \\
\text { decreases by } 10 \%\end{array}$ & [112] \\
\hline & Systematic review of $15 \mathrm{RCTs}$ & $\begin{array}{l}10-50 \mathrm{~mL} / \text { day EVOO reduced diastolic } \\
\text { blood pressure by } 0.7 \mathrm{~mm} \mathrm{Hg}\end{array}$ & [113] \\
\hline & $\begin{array}{l}\text { Meta-analysis of } 9 \text { studies ( } 38,673 \text { stroke } \\
\text { and 101,460 CHD cases from RCT, } \\
\text { case-control and prospective studies) }\end{array}$ & $\begin{array}{c}\text { For every increase of } 25 \mathrm{~g} \text { of olive oil } \\
\text { consumption the risk of CVD, stroke and } \\
\text { CHD was reduced by } 18 \%, 26 \% \text { and } \\
4 \% \text { respectively }\end{array}$ & [114] \\
\hline & Meta-analysis of $26 \mathrm{RCTs}$ & $\begin{array}{l}\text { High polyphenol olive oil intake } \\
\text { significantly reduced CVD and } \\
\text { inflammatory markers }\end{array}$ & [115] \\
\hline \multirow{4}{*}{ Antioxidant properties } & $\begin{array}{l}\text { European Food Safety Authority } \\
\text { health claim. }\end{array}$ & $\begin{array}{l}5 \mathrm{mg} / \text { day of olive oils polyphenols protects } \\
\text { blood lipids from oxidation }\end{array}$ & [116] \\
\hline & $\begin{array}{l}\text { RCTs evaluating the effect of olive oils } \\
\text { consumption on blood lipids } \\
\text { oxidative state. }\end{array}$ & $\begin{array}{l}\text { EVOO and high-phenolic olive oils } \\
\text { consumption reduces LDL oxidation in a } \\
\text { dose-dependent manner }\end{array}$ & [117-120] \\
\hline & $\begin{array}{l}\text { Controlled trials with sub-samples of } \\
\text { PREDIMED cohort }(n=296) \text { and }(n=210)\end{array}$ & $\begin{array}{c}\text { Adherence to a MED enriched with EVOO } \\
\text { improves HDL function and protects } \\
\text { against LDL oxidation }\end{array}$ & {$[108,109]$} \\
\hline & In vitro studies review. & $\begin{array}{l}\text { Lignans present in EVOO show antioxidant } \\
\text { activity in vitro }\end{array}$ & [121] \\
\hline \multirow{3}{*}{$\begin{array}{l}\text { Anti-inflammatory } \\
\text { capacity }\end{array}$} & Meta-analysis of 13 studies based on 9 RCTs & $\begin{array}{l}\text { Regular consumption of EVOO reduces } \\
\text { IL-6, CRP and TNF- } \alpha \text { levels }\end{array}$ & [122] \\
\hline & Meta-analysis of RCTs (3106 participants) & $\begin{array}{l}\text { Diet supplemented or enriched in olive oil } \\
\text { reduces IL-6 and CRP plasmatic levels }\end{array}$ & [123] \\
\hline & Randomized crossover study (49 patients) & $\begin{array}{l}\text { High-phenolic virgin olive oil in breakfast } \\
\text { reduces postprandial } \\
\text { inflammatory response. }\end{array}$ & [124] \\
\hline \multirow{5}{*}{ Antitumoral activity } & $\begin{array}{l}\text { Meta-analysis of } 19 \text { case-control studies } \\
\text { (comprising 13,800 cancer cases and } \\
23,340 \text { controls) }\end{array}$ & $\begin{array}{c}\text { Olive oil consumption is associated with } \\
\text { lower odds of developing digestive and } \\
\text { breast cancers }\end{array}$ & [125] \\
\hline & $\begin{array}{l}\text { Cohort-study follow up ( } 2321 \text { breast cancer } \\
\text { cases and } 1665 \text { controls) and meta-analysis }\end{array}$ & $\begin{array}{l}\text { Inverse association between adherence to } \\
\text { MED and ERN breast cancer }\end{array}$ & [126] \\
\hline & $\begin{array}{l}\text { RCT with a sub-sample of the PREDIMED } \\
\text { cohort ( } n=4152 \text { women) }\end{array}$ & $\begin{array}{l}\text { Women following MED enriched in EVOO } \\
\text { showed } 62 \% \text { relatively lower risk of breast } \\
\text { cancer compared to control low-fat diet }\end{array}$ & [110] \\
\hline & $\begin{array}{c}\text { Systematic review and meta-analysis of } 83 \\
\text { studies, comprising a total of } \\
2,130,753 \text { subjects }\end{array}$ & $\begin{array}{l}\text { The adherence to MED is associated with } \\
\text { lower risk of cancer mortality and lower } \\
\text { risk of breast, colorectal, gastric and liver } \\
\text { cancers, among others }\end{array}$ & [127] \\
\hline & $\begin{array}{l}\text { In vitro experiments of antitumoral activity } \\
\text { of phenolic compounds on cancer cell lines }\end{array}$ & $\begin{array}{l}\text { The phenolic fraction of EVOO, as well as } \\
\text { isolated phenolic compounds, shows } \\
\text { antitumoral and cytotoxic effect on different } \\
\text { cancer cell lines }\end{array}$ & [128-130] \\
\hline \multirow[t]{2}{*}{$\begin{array}{l}\text { Gut microbiota } \\
\text { modulation }\end{array}$} & $\begin{array}{c}\text { RCT with } 12 \text { hypercholesterolemic } \\
\text { participants }\end{array}$ & $\begin{array}{c}\text { Virgin olive oil enriched in phenolic } \\
\text { compounds consumption favors gut } \\
\text { bifidobacteria growth and decreases serum } \\
\text { levels of oxidized LDL }\end{array}$ & [131] \\
\hline & $\begin{array}{l}\text { Systematic review and meta-analysis of } \\
17 \text { RCTs }\end{array}$ & $\begin{array}{l}\text { Polyphenols exert a prebiotic action on gut } \\
\text { microbiota, improving also CVD and CRC }\end{array}$ & [132] \\
\hline
\end{tabular}

EVOO: extra virgin olive oil; CVD: cardiovascular disease; CHD: coronary heart disease; RCT: randomized controlled trial; MED: Mediterranean diet; HDL: high-density lipoprotein; LDL: low-density lipoprotein; IL-6: interleukin-6; CRP: C-reactive protein; TNF- $\alpha$ : tumor necrosis factor alpha; IBD: inflammatory bowel disease; ERN: estrogen receptor negative; $\mathrm{CRC}$ : colorectal cancer.

\subsection{Cardioprotective Properties}

The Seven Country Study started in the 1950s first demonstrated the cardioprotective abilities of MED [106] and has been supported by numerous further studies based both on MED and olive oil consumption. 
More recently, the cardioprotective benefits of a MED enriched with EVOO have been proven by the PREDIMED study. This multicenter, randomized, controlled trial involved $~ 7500$ subjects with potential cardiovascular risk, showing no CVD at enrolment. The PREDIMED trial resulted in a 30\% decrease of a major CVD development, such as stroke or myocardial infarction, in comparison to a control group that followed a low-fat diet $[30,107]$. An observational study based on the PREDIMED cohort indicated that consumptions of $10 \mathrm{~g} \mathrm{EVOO/day} \mathrm{are} \mathrm{related} \mathrm{to} \mathrm{CVD} \mathrm{risk} \mathrm{diminutions} \mathrm{up} \mathrm{to}$ $10 \%$ [112]. A recent systematic review evaluating clinical trials reported that diets enriched with $10-50 \mathrm{~mL} /$ day of EVOO (but not diets supplemented with EVOO capsules) significantly decreased diastolic blood pressure by $0.73 \mathrm{~mm} \mathrm{Hg}$ [113].

In another meta-analysis of randomized controlled trials, case-control and prospective cohort studies including $\sim 40,000$ cases of stroke and $\sim 100,000$ cases of coronary heart disease (CHD), it was reported that for each increase of $25 \mathrm{~g}$ of olive oil intake, stroke and CHD risk was reduced by $26 \%$ and $4 \%$, respectively. When combined stroke and CHD, olive oil consumption also showed preventing effects, decreasing the risk of a CVD event by approximately $18 \%$ [114].

The preventive role of EVOO polyphenols against CVD was also documented in a meta-analysis of controlled trials that evaluated the effect of low versus high polyphenol olive oil on markers of CVD risk. Olive oil consumption ranged from $25-75 \mathrm{~mL}$ /day. High polyphenol olive oil significantly reduced the CVD-risk markers malondialdehyde, oxidized LDL, total cholesterol, high-density lipoprotein (HDL) cholesterol and also some inflammatory indicators like C-reactive protein (CRP) or interleukin-6 (IL-6) [115].

\subsection{Antioxidant Activity}

The antioxidant effects of EVOO have been deeply analyzed given the correlation between oxidative stress and CVD or atherosclerosis. Evidence from several meta-analyses and randomized controlled trials, such as the EUROLIVE study $[117,119]$, demonstrated in their analyses the reduction of lipid oxidative damage, the LDL capacity to suffer oxidation and a decrease in oxidized LDL concentration after high-phenolic VOO and EVOO intake, in a dose-dependent way $[118,120]$. It is also worth noting the health claim allowed by the European Food Safety Authority (EFSA) concerning the protective effects of $5 \mathrm{mg} /$ day of olive oil phenolic compounds against LDL oxidation [116]. The PREDIMED cohort was also used to evaluate the antioxidant effects of EVOO. The intervention group with MED enriched with EVOO reported an improvement of HDL atheroprotective functions, oxidative status and composition and also increased resistance to LDL oxidation and low grade of LDL oxidative alterations in comparison to the control low-fat diet $[108,109]$.

Pinoresinol and acetoxypinoresinol, phenolic compounds present in EVOO but not in olive fruits or refined oils, isolated from EVOO or other sources such as sesame seed, have reported in vitro antioxidant capacity [121]. The enzymatic hypoxanthine/xanthine oxidase assay reported a higher antioxidant potential of acetoxypinoresinol, compared to the classic antioxidants, vitamin $\mathrm{E}$ and dimethylsulfoxide ( $\mathrm{IC}_{50}$ of $0.91,12.4$ and $2.30 \mathrm{nM}$, respectively). Pinoresinol possesses the ability to inhibit LDL oxidation but has shown inconsistent results ( $\mathrm{IC}_{50}$ ranging from $24.6-558 \mu \mathrm{M}$, 2,2-Diphenyl-1-picryl-hydrazyl-hydrate free radical assay (DPPH) colorimetric assay).

\subsection{Anti-Inflammatory Activity}

Recurrent or chronic inflammation is a main etiologic factor of several non-communicable pathologies, whose prevalence is promptly increasing. Thus, the anti-inflammatory effects of EVOO have gained attention and so have been widely evaluated.

A recent meta-analysis of randomized controlled trials evaluated regular olive oil intake effects on inflammation [122]. The authors reported a decrease in the levels of IL-6, tumor necrosis factor- $\alpha$ (TNF- $\alpha$ ) and CRP, the three plasmatic inflammatory indicators considered. Such beneficial effects were shown in studies when EVOO was regularly consumed for more than 3 months. The overall health status of participants should also be taken into account, as the strongest positive effects were reported 
among unhealthy groups (with type 2 diabetes mellitus or at risk of CVD). Another meta-analysis comprising 3106 participants also showed a significant reduction of IL-6 and CRP levels, when olive oil was consumed as a supplementary or natural intake [123]. The adherence to a high-phenol VOO breakfast decreased the postprandial inflammatory response, reducing the levels of plasma lipopolysaccharides in patients with metabolic syndrome [124]. The higher polyphenol content of EVOO may mediate the mentioned favorable effect as it has demonstrated anti-inflammatory effects in vitro [133]. The anti-inflammatory effect of phenolic compounds-enriched EVOO has also been reported in the adipose tissue in mice, with anti-atherosclerotic effects [134].

Due to these mentioned capacities, EVOO has also been proposed as a potential therapeutic product, reducing inflammation in inflammatory bowel diseases, including ulcerative colitis and Crohn's disease, being both related to chronic inflammation of the intestinal mucosa $[135,136]$. The benefits of EVOO consumption were evaluated in other autoimmune and chronic inflammatory diseases such as rheumatoid arthritis [137], systemic lupus erythematosus [138] or multiple sclerosis [139,140] with promising results in murine models. Besides, both in vitro and in vivo studies outline that the anti-inflammatory activity of EVOO provides a neuroprotective effects that could prevent cognitive decline and, therefore, the development of Alzheimer's disease or elderly dementia [3,141].

\subsection{Antitumoral Activity}

Traditionally, a lower incidence of cancers such as breast, colorectal, endometrium and prostate cancer has been observed in Mediterranean countries linked to dietary factors, when compared to the USA or other European countries [142]. The antitumoral and anticancer activities of EVOO, as well as of specific fractions or isolated compounds, have been widely studied and evidenced both in vitro with cell cultures and in vivo with animal models, observational cohort studies and clinical trials [143].

Evidence from 19 case-control observational studies, including in total 13,800 cancer cases and 23,340 controls, suggests that olive oil intake is inversely associated with the risk of having any type of cancer (34\% lower likelihood of cancer for high olive oil intake) [125]. More precisely, this meta-analysis associated lower odds for developing breast and digestive cancer with olive oil consumption (log odds ratio of -0.45 and -0.36 , respectively).

The strongest beneficial effects of EVOO concerning cancer have been described in breast cancer prevention. A meta-analysis reported a statistically significant inverse association between estrogen receptor-negative postmenopausal breast cancer and the adherence to MED [126]. Breast cancer incidence was also included in the PREDIMED trial, which included $\sim 4200$ women. Those allocated to the MED enriched with EVOO showed a $62 \%$ relatively lower risk of breast cancer, compared to women who followed a low-fat diet $[107,110]$. To our knowledge, no recent large case-control or prospective cohort studies have been conducted about the relationship between colorectal cancer risk and EVOO consumption. Nevertheless, a meta-analysis has determined that MED consumption is related to a $14 \%$ lower risk or developing colorectal cancer [127]. Recently, it has been suggested that the antitumoral activity of EVOO, lowering colorectal tumor incidence in rats, could be mediated by epigenetic mechanisms, such as miRNA and deoxyribonucleic acid (DNA) methylation [144].

In vitro experiments have shown that both the phenolic fraction of EVOO and specific compounds such as hydroxytyrosol, caffeic acid, p-Coumaric acid, 1-acetoxypinoresinol and pinoresinol, among others, have antitumoral activity against breast cancer cell lines $[128,129]$. Other in vitro studies about the cytotoxic effect of the EVOO lignan pinoresinol have reported variable results, depending on the cancer cell line tested. Pinoresinol shows a cytotoxic effect against breast, lung and prostate cell lines, and it inhibits cell viability of colon cancer cells. A synergic effect with other EVOO phenolic compounds have been reported $[121,130]$.

\subsection{Positive Modulation of Gut Microbiota}

Much of the health benefits of olive oil consumption are attributed to the metabolism of the phenolic compounds carried out by the gut microbiota [145]. It is estimated that $90-95 \%$ of total 
phenolic compounds intake is not absorbed in the small intestine; therefore, they remain in the large intestinal lumen where they are subjected to gut microbiota metabolic activities. As a consequence, polyphenols are converted to low-molecular-weight compounds that are absorbed and responsible for the health benefits derived from polyphenol-rich food, such as EVOO [132,146,147].

A recent review and meta-analysis of randomized controlled trials supports the prebiotic action of polyphenols, capable of modulating and improving intestinal microbe populations, which affects to CVD and colorectal cancer markers [132]. Furthermore, another randomized controlled trial showed that the ingestion of $\mathrm{VOO}$ enriched with phenolic compounds decreases the serum levels of oxidized LDL in hypercholesterolemic participants as well as increases the presence of Bifidobacterium spp in feces. Slight changes in the profile of fecal microbial metabolites were also reported. These data suggest that the cardioprotective effect of phenolic compounds could be mediated by the populations of bifidobacteria present in the gut microbiota [131]. The possible modulation of gut microbiota by olive oil and its role in cancer prevention, especially colorectal cancer, has also been suggested [148].

However, the complexity of the human diet, the lack of accuracy in the measurement of dietary intake and the extensive variation on microbiota between individuals challenges the evaluation of how diet changes modulate gut microbiota and its metabolic activity [149].

\subsection{Other Bioactivities}

The detailed description above was limited to the main bioactivities attributed to EVOO and its specific components. However, some other activities of biological relevance are under study. A recent extensive review highlighted the anti-aging properties of the major phenolic compound in EVOO, hydroxytyrosol, suggesting that it can contribute to the correct regulation of mechanisms that maintain cell homeostasis, such as mitogen-activated protein kinase (MAPK) and mammalian target of rapamycin (mTOR) pathways, whose imbalance is a hallmark of aging [150]. Moreover, this phenolic compound also modulates the metabolism of adipose tissue, stimulating mitochondrial biosynthesis and increasing the function of the mitochondrial respiratory chain in vitro [151].

EVOO consumption has also been associated with the enhancement of blood circulation and coagulation, by reducing platelet aggregation (mechanism related to CVD) and decreasing the levels of coagulation factor VII, effects attributed to minor components of EVOO [12]. Interestingly, a study carried out in murine models reported that polyphenols present in EVOO may improve learning and memory, by reversing the oxidative damage in the brain associated with aging and diseases related to the production of amyloid- $\beta$ protein [152].

As a final remark, hydroxytyrosol, pinoresinol and oleuropein from EVOO have been reported to possess antimicrobial capacity. Pinoresinol has shown antifungal activity against several pathogenic fungi such as Fusarium verticillioides, Fusarium graminearum and Candida albicans [121]. Additionally, oleuropein and hydroxytyrosol were found to be effective against fungi and several strains of bacteria, viruses, including human immunodeficiency viruses (HIV) and parasites [151,153].

\section{EVOO Quality Regarding the Chemical Composition}

As aforementioned, olive oil qualification as "extra virgin" demands various requisites. On one hand, it must be obtained using exclusively mechanical procedures, which grants the "virgin" label. On the other hand, it must show a low free acidity $(<0.8 \%)$, low peroxide value, high antioxidant activity, a perceptible fruity taste and no sensory defects, acquiring in this way the label "extra". However, once those badges are achieved, it is important to attend to some storage factors to maintain and assure these quality characteristics until the oil is used [154,155]. Figure 4 shows a summary concerning the quality-involved parameters. 


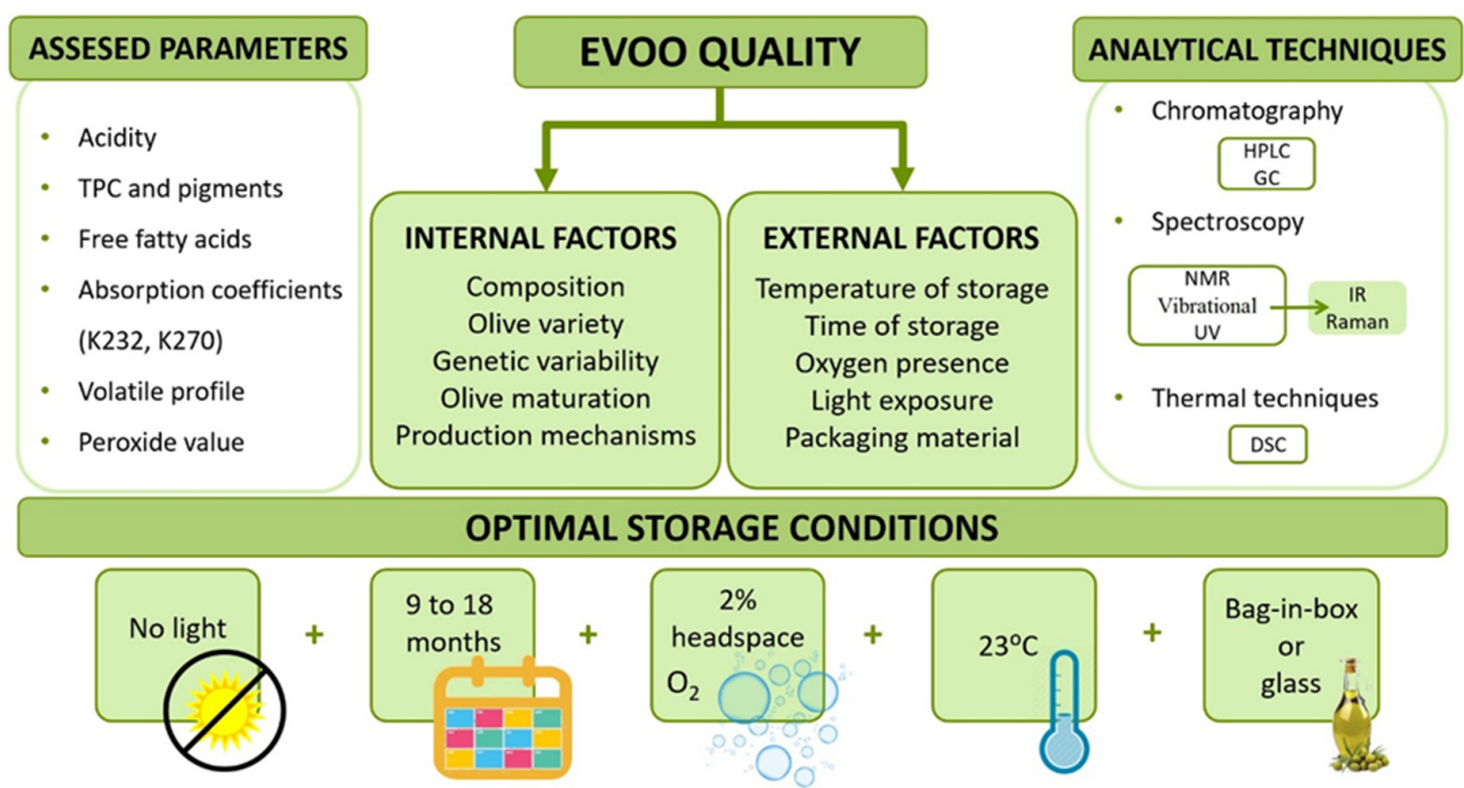

Figure 4. Parameters and factors concerning EVOO quality and its preservation.

\subsection{Analytical Techniques}

Parameters usually taken as EVOO quality indicators, as well as authenticity and fraud control markers are acidity, peroxide value, absorption coefficients $K_{232}$ and $K_{270}$, color, total phenolic content (TPC), fatty acids composition and volatile compounds' profile. Spectrophotometric techniques are the most used to perform stability and quality analysis of EVOO since they are based on quick, simple, cheap and non-destructive methodologies offering the possibility of executing real-time controls. Several compounds are studied through these methodologies, such as certain pigments (chlorophylls, pheophytins, carotenoids, etc.) which are an easy and quick way to assess the degradation of EVOOs caused by temperature and/or light. The absorbance range analyzed for this purpose is between 350 and $750 \mathrm{~nm}[154,156]$.

Phenolic compounds, in addition of being responsible for a large part of the beneficial effects of EVOO, actively intervene in its quality, extending its useful life thanks to its antioxidant power [157]. This is the reason why its concentration is analyzed as a quality measure since the loss of these compounds is parallel to the degradation of EVOO. They are usually analyzed spectrophotometrically following the Folin-Ciocalteu method, as TPC (at absorbances of $\sim 750 \mathrm{~nm}$ ) and using gallic acid as standard, a methodology that offers speed, ease and reproducibility [155].

For the subsequent analysis of visible spectroscopy data and the prediction of optimal storage conditions, it is possible to use certain mathematical tools, such as multilayer perceptrons, capable of finding non-linear relationships between the variables involved, whether dependent or independent, based on artificial neural networks. Despite being a tool with many chemical applications including the food industry, it is important to add that it does not provide very reliable extrapolations since the model is based reliably on the breadth of the experimentally studied data [154,158].

Other analytical techniques that can be used are high-performance liquid chromatography or gas chromatography (HPLC, GC), nuclear magnetic resonance (NMR), differential scanning calorimetry (DSC) or vibrational spectrometry, which includes Raman and infrared spectrometry. These processes are more accurate when quantification is desired, although they are also more time-consuming, they require more specific types of equipment and are usually aimed at determining the origins of the EVOO or performing anti-fraud controls [159,160].

As an innovative and emerging methodology, it is worth highlighting the use of chemosensors and biosensors. These devices were initially based on electrochemical detection but have evolved in the direction of being coupled to smartphones, allowing to combine spectrophotometric techniques 
with optical image detection from the smartphone's camera, resulting in on-site analysis of samples without requiring any pretreatment and without the need for a laboratory environment $[155,161]$.

\subsection{Effect of Olive Variety}

As expected, the variety of olives used to produce EVOO determines its final composition, constituting an internal factor that influences stability and quality $[162,163]$. Not only the variety but also the geographical location and the growing conditions, as well as the applied mechanical production process, affect its quality $[51,164,165]$. Taking all these variables into account, it is possible to obtain EVOOs with different concentrations of compounds in such wide ranges as $50.5-80.5 \%$ for oleic acid, 91-665 mg/kg for $\alpha$-tocopherol and 50-900 mg/ $/ \mathrm{kg}$ for secoiridoid derivatives and lignans [166]. As an example, two varieties are discussed in this section, Empeltre varietal and Manzanilla Cacereña varietal. Based on the analyzes performed by visible spectrophotometry Manzanilla varietal contains a major amount of pigments (chlorophylls and their derivatives such as pheophytins, as well as carotenoids), and greater absorbance is observed on EVOO produced using Manzanilla Cacereña varietal. This fact also affects EVOO's coloration, since the greater the number of pigments, the more yellowish-greenish the tonality. Likewise, a higher density is also observed in the liquid produced with the variety of olives that present a higher concentration of pigments [154].

Another study based on the comparison of EVOOs from two different varieties, Manzanilla and Picual, determined that the Manzanilla variety has a higher PUFA content and a lower MUFA content than the Picual variety, although a decrease in MUFA was found proportional to the increase in PUFA during degradation of both types of EVOO. Similarly, the Picual variety shows a higher content of polyphenols than Manzanilla, and therefore, a higher antioxidant activity. According to these authors, the compounds most influenced by the variety of olive used are fatty acids [167].

Therefore, the amount of oleic acid and natural antioxidant compounds, namely tocopherols and phenolic compounds and particularly, oleuropein, that are present in the final composition of the EVOO, is directly proportional to its better resistance to degradation. This fact is due to their capacity to avoid the formation of volatile compounds, responsible for the rancidness defect, and consequently enhance its shelf-life [166,168].

\subsection{Effect of Light}

Exposure to sunlight is one of the main factors that promote and accelerate the degradation of chemical compounds, such as pigments or phenolic compounds. Besides, it is one of the key factors as the EVOO is highly exposed to light during its stay in supermarkets and points of sale [169]. A study that analyzed the effect of light in 14 commercial varieties of EVOOs, recreating the conditions to which they are subjected in stores for 6 months, showed that light has a greater degrading effect on those compounds that contribute to the health-promoting properties, such as phenolic compounds, than on the compounds responsible for its quality, like acidity or oleic acid content. The quantification of the different analyzed compounds: oleic acid, total phenolic compounds, MUFA, PUFA, $\alpha$-tocopherol, lignans and oleuropein, was carried out using HPLC and concluded that the loss of the "extra" condition can be predicted in time according to the initial concentration of oleuropein that a certain EVOO presents, thus this compound shows a strong antioxidative power [166]. Another fast and efficient way to perform light degradation analysis is by measuring pigments, such as chlorophyll. Nevertheless, light exposure is not recommended during the storage period if extending EVOO's shelf-life and preserving its properties is desired [170,171].

\subsection{Effect of Temperature}

Another factor to consider during EVOO conservation is temperature. Several studies carried out with different EVOOs from different sources (Almazara del Ebro and As Pontis) highlight this fact. Comparing the absorption spectra in the visible ultraviolet of the oils, temperatures close to 
$40{ }^{\circ} \mathrm{C}$ cause greater adulterations in the composition of pigments than low temperatures, such as $3{ }^{\circ} \mathrm{C}$, although the ideal temperature for its conservation is around $23^{\circ} \mathrm{C}[154,172]$.

As a curious fact, when EVOO is stored at low temperatures, a crystallization process caused by freezing can be observed. In this process, triacylglycerols start to freeze through the methyl fraction, which is just the part that melts first in the opposite process. Through the analysis of the freezing and melting kinetics, information related to the geographical origin of the EVOO can be obtained $[160,173]$. Moreover, low temperatures application during EVOO processing has shown to be an effective strategy to improve its yield and quality [174].

\subsection{Effect of Time}

Time, as in most aspects of life, also plays a key role in the quality of the EVOO. Generally speaking, the shelf life of EVOOs is between 9 and 18 months, depending on other concomitant factors such as temperature or chemical composition, since when it is stored at $3^{\circ} \mathrm{C}$ or room temperature, less degradation is observed than at $40^{\circ} \mathrm{C}$ during the same period analyzed ( 88 days). In the same way, depending on the nature of the compounds that are present, they will suffer more or less degradation over time. Going back to previous examples, EVOOs obtained from the Empeltre and Manzanilla Cacereña varieties suffered different degradations under the same conditions: the Manzanilla Cacereña variety generated an EVOO whose visible absorption spectrum suffered a drastic decline in the first 10-12 days of storage after opening the bottle, regardless of temperature, while the Empeltre variety maintained a more linear spectrum over time, suggesting that the Manzanilla variety contained more easily degradable compounds [154]. Likewise, a longer study in time, in which the degradation suffered by 14 varieties of commercial EVOOs during 22 months of storage in the absence of light and at room temperature was analyzed, showed that peroxide values increase proportionally with storage time, so it is recommended that consumption occurs as close as possible to the production process [175].

\subsection{Effect of Oxygen Presence}

Oxygen presence is an essential factor in the oxidative degrading process. Moreover, EVOO oxygen content once produced, oxygen permeability while packaging and headspace oxygen are important factors influencing deterioration of lipids and overall EVOO quality and shelf-life during storage [169]. A study conducted on the effect of headspace oxygen concentration and the presence of light on the quality of EVOO over time determined that the shelf life of EVOO could be maximized, exceeding 12 months of stability, by applying headspace oxygen between $2 \%$ and $5 \%$. However, intending to preserve the majority of beneficial compounds possible, such as pigments and polyphenols, it is preferable to carry out preservation in the absence of light and at low temperatures, around $10{ }^{\circ} \mathrm{C}$, as well as using headspace oxygen of $2 \%$. For this purpose, modified atmosphere packaging can be used, in which oxygen is replaced by other inert gases such as argon or helium [176].

\subsection{Effect of Packaging Material}

Finally, another external factor that influences the quality of the EVOO over time is the packaging material chosen. Some of the materials of choice for this purpose are tinted glass, polyethylene terephthalate (PET), tinplate, aluminum, tetra bricks or bag-in-box packages [177]. Various studies position glass as one of the materials that best preserves EVOO, since it is an inert material and, being tinted, reduces the passage of light. On the other hand, polypropylene and polyethylene are materials that show high oxygen permeability, so they are not recommended when preserving EVOO properties for a long time $[169,178]$. However, as happened before, this factor also depends on other conditions. The use of bag-in-box packages at home environment between 22 and $37^{\circ} \mathrm{C}$ seems to benefit the preservation and lengthening of the EVOO shelf-life, as demonstrated in a study in which this packaging method was compared to tinplate steel containers [179]. 


\section{Possible Applications of EVOO beyond Nutritional Purposes}

\subsection{Extractive Solvent}

EVOO used in preparing culinary dishes offers numerous advantages, whether the implicit biological activities listed above or certain physicochemical characteristics that become indirectly beneficial. An example is the extractive capacity of some lipophilic compounds contained in the rest of the ingredients present in the recipes, managing to isolate them from the protection of the original matrix and, therefore, increase their bioavailability in the body, as occurs with lycopene present in tomato, the largest known source of this compound. This transfer of the lycopene from the tomato to the EVOO is achieved with a simple application of microwave heat to the food which additionally favors its isomerization, obtaining Z-Lycopene, the isomer that is mostly absorbed and is found in plasma. Hence, this EVOO capacity could be used to maximize extractive processes of certain lipophilic molecules, allowing their safe application in the food industry and avoiding the use of contaminating organic solvents [180].

\subsection{Therapeutic Application}

As previously mentioned, the bioactivities associated with EVOO are numerous, many related to its antioxidant capacity. The inclusion of EVOO in the daily diet supposes health benefits and helps to prevent the appearance of certain diseases such as heart and vascular, neurodegenerative, cytotoxic, metabolic and inflammatory diseases, among others, $[3,181]$ due to its content in functional compounds such as polyphenols, tocopherols, carotenoids, sterols, fatty acids, squalene, etc. Therefore, EVOO becomes an attractive candidate for possible applications in therapeutics, constituting a potential strategy to use it in certain treatments that require its properties [182]. An example of this is a study conducted on the ability of EVOO to counteract the effect of chromium poisoning, a compound classified among the 20 most dangerous for humans and for the environment by the Agency for Toxic Substances and Disease Registry (ATSDR), which is capable of causing both acute and chronic toxicity, depending on the exposure. Some of the damages it causes in humans are neurotoxicity, genotoxicity, carcinogenicity, dermatotoxicity, or hepatotoxicity. So the oral administration of $300 \mu \mathrm{L}$ of EVOO in animal models of rats previously intoxicated with chromium manages to reduce the genotoxic, immunotoxic and cytotoxic effects of the most harmful form of this compound, its hexavalent derivative, reducing the consequences of punctual or prolonged exposure [183].

Another way of approaching this point is the addition of more beneficial compounds to EVOO since it is a product daily consumed in many countries, which means transforming it into a vehicle enriched with functional compounds so that the health-promoting effects that EVOO already owns per se are increased [184]. An effective approach to incorporate such compounds into EVOO is using encapsulation, which preserves them from becoming rancid while improving the stability of those functional compounds such as vitamins or calcium [185-187].

\section{Conclusions}

EVOO, also colloquially known as "liquid gold" is a natural product of unquestionable value and not only in the monetary sense of the term but also for its recognized properties and advantages on health. It is considered food for its nutritional value and is practically a requirement of the MED, contributing to the benefits associated with it. Its chemical composition allows EVOO to be classified as a lipophilic product since lipids are the main compounds, especially MUFA, followed by PUFA. This lipid fraction is responsible for protective properties on coronary, autoimmune and inflammatory disorders, granting anti-thrombotic and regulation effects of blood pressure Although in a smaller quantity, other compounds such as tocopherols or polyphenols are also present, which are associated with the powerful antioxidant and inflammatory activity of EVOO, among other qualities. For all these reasons, the inclusion of this golden ingredient in the diet, in addition to offering characteristic organoleptic properties, provides substances capable of preventing the appearance or development 
of diseases of various nature, from heart and circulatory diseases to metabolic disorders, including carcinogenic processes. Compared to other types of olive oil, EVOO must meet more stringent requirements that give it the right to possess that nomenclature. However, it is a shame that, during distribution and storage, the previously achieved quality is corrupted, leaving some of its most distinguished and desirable properties on the way. Therefore, the factors that promote the degradation of its components must be known, intending to reduce the negative impact that may originate in EVOO and thus increasing its shelf-life. These factors can be divided into intrinsic factors, such as the variety of olives and their cultivation conditions, about which little can be done once EVOO has been produced; and external factors, which include exposure to light, temperature, time or the type of material used for packaging. Due to the functional properties it presents, other applications for EVOO could also be considered, such as its use in therapies in which other treatments are not very effective, like certain neurodegenerative diseases or as a vehicle for the administration of certain pharmacological compounds in a comfortable way, by simply adding them to the diet. Future studies aimed at optimizing and maximizing the capabilities and applications of this product will, without a doubt, be welcomed and well received by the industry, not only food and agriculture but also by the pharmaceutical and cosmetics industries.

Author Contributions: Formal analysis, M.A.P., J.S.-G., C.J.-L., M.C., C.L.-L., M.G.-G., J.M.L. and F.J.B.; investigation, C.J.-L., M.C., C.L.-L., M.G.G. and F.J.B.; methodology, C.J.-L., M.C., C.L.-L., M.G.-G., J.M.L. and F.J.B.; supervision, M.A.P. and J.S.G.; validation, M.A.P. and J.S.G.; writing—original draft, M.A.P., J.S.-G., C.J.-L., M.C., C.L.-L., M.G.-G. and F.J.B.; writing—review and editing, M.A.P. and J.S.-G. All authors have read and agreed to the published version of the manuscript.

Funding: The research leading to these results received financial support from Programa de Cooperación Interreg V-A España-Portugal (POCTEP) 2014-2020 (projects Ref.: 0181_NANOEATERS_01_E and Ref: 0377_IBERPHENOL_6_E) supporting the pre-doctoral work of C.J.L. To MICINN supporting the Ramón\&Cajal grant for M.A.P. (RYC-2017-22891); to the company AlgaMar (www.algamar.com) and Axudas Conecta Peme (Xunta de Galicia) supporting the IN852A 2018/58 NeuroFood Project that financed the pre-doctoral grant for C.L.L.; to EcoChestnut Project (Erasmus+ KA202) for supporting the work of M.C.R.; to Ibero-American Program on Science and Technology (CYTED-AQUA-CIBUS, P317RT0003) for financial support. This project has received funding from the Bio Based Industries Joint Undertaking (JU) under grant agreement No 888003 UP4HEALTH Project (H2020-BBI-JTI-2019), the JU receives support from the European Union's Horizon 2020 research and innovation program and the Bio Based Industries Consortium.

Conflicts of Interest: The authors declare no conflict of interest.

\section{Abbreviations List}

$\begin{array}{ll}\text { Generic } & \\ \text { CHD } & \text { Coronary Heart Disease } \\ \text { CVD } & \text { Cardiovascular Diseases } \\ \text { DSC } & \text { Differential Scanning Calorimetry } \\ \text { DPPH } & \text { 2,2-Diphenyl-1-picryl-hydrazyl-hydrate free radical assay } \\ \text { EFSA } & \text { European Food Safety Authority } \\ \text { EU } & \text { European Union } \\ \text { EVOO } & \text { Extra Virgin Olive Oil } \\ \text { GC } & \text { Gas Chromatography } \\ \text { HPLC } & \text { High Performance Liquid Chromatography } \\ \text { HIV } & \text { Human Immunodeficiency Viruses } \\ \text { IC } & \text { Half Maximal Inhibitory Concentration } \\ \text { IOC } & \text { International Olive Council } \\ \text { MED } & \text { Mediterranean Diet } \\ \text { NMR } & \text { Nuclear Magnetic Resonance } \\ \text { PREDIMED } & \text { Prevention Through Mediterranean Diet } \\ \text { USA } & \text { United States of America } \\ \text { VOO } & \text { Virgin Olive Oil }\end{array}$




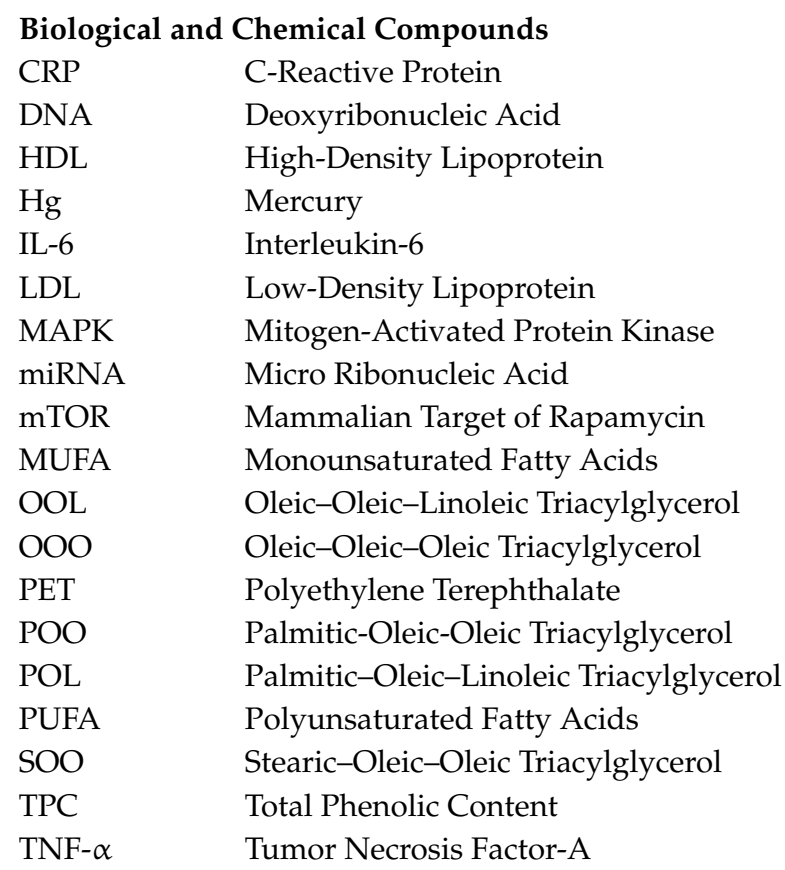

\section{References}

1. Foscolou, A.; Critselis, E.; Panagiotakos, D. Olive oil consumption and human health: A narrative review. Maturitas 2018, 118, 60-66. [CrossRef] [PubMed]

2. Oliveras-López, M.J.; Berná, G.; Jurado-Ruiz, E.; López-García de la Serrana, H.; Martín, F. Consumption of extra-virgin olive oil rich in phenolic compounds has beneficial antioxidant effects in healthy human adults. J. Funct. Foods 2014, 10, 475-484. [CrossRef]

3. Román, G.C.; Jackson, R.E.; Reis, J.; Román, A.N.; Toledo, J.B.; Toledo, E. Extra-virgin olive oil for potential prevention of Alzheimer disease. Rev. Neurol. 2019, 175, 705-723. [CrossRef] [PubMed]

4. European Comission. EU Olive Oil Farms Report Based on FADN Data. L.3. Microeconomic Analysis of EU Agricultural Holdings; European Comission: Brussels, Belgium, 2012; p. 80.

5. Rossi, R. The EU olive and olive oil sector: Main features, challenges and prospects. In European Parliamentary Research Service; European Parliament: Brussels, Belgium, 2017; p. 12.

6. Letendre, D. Les mots de l'insoumis. Liberte 2014, 47, 278.

7. Urpi-Sarda, M.; Casas, R.; Chiva-Blanch, G.; Romero-Mamani, E.S.; Valderas-Martínez, P.; Arranz, S.; Andres-Lacueva, C.; Llorach, R.; Medina-Remón, A.; Lamuela-Raventos, R.M.; et al. Virgin olive oil and nuts as key foods of the Mediterranean diet effects on inflammatory biomakers related to atherosclerosis. Pharm. Res. 2012, 65, 577-583. [CrossRef]

8. Ruiz-Canela, M.; Martínez-González, M.A. Olive oil in the primary prevention of cardiovascular disease. Maturitas 2011, 68, 245-250. [CrossRef]

9. Musumeci, G.; Trovato, F.M.; Pichler, K.; Weinberg, A.M.; Loreto, C.; Castrogiovanni, P. Extra-virgin olive oil diet and mild physical activity prevent cartilage degeneration in an osteoarthritis model: An in vivo and in vitro study on lubricin expression. J. Nutr. Biochem. 2013, 24, 2064-2075. [CrossRef]

10. Seçmeler, Ö.; Galanakis, C.M. Chapter 8-olive fruit and olive oil. In Innovations in Traditional Foods; Woodhead Publishing: Sawston, UK, 2019; pp. 193-220, ISBN 9780128148884.

11. Pérez-Rodrigo, C.; Aranceta, J. Olive oil: Its role in the diet. In The Encyclopedia of Healing Foods; Atria Books: New York, NY, USA, 2015; pp. 158-166.

12. Yubero-Serrano, E.M.; Lopez-Moreno, J.; Gomez-Delgado, F.; Lopez-Miranda, J. Extra virgin olive oil: More than a healthy fat. Eur. J. Clin. Nutr. 2019, 72, 8-17. [CrossRef]

13. Beltrán, G.; Del Rio, C.; Sánchez, S.; Martínez, L. Influence of harvest date and crop yield on the fatty acid composition of virgin olive oils from cv. Picual. J. Agric. Food Chem. 2004, 52, 3434-3440. [CrossRef] 
14. Inglese, P.; Famiani, F.; Galvano, F.; Servili, M.; Esposto, S.; Urbani, S. Factors Affecting Extra-Virgin Olive Oil Composition. In Horticultural Reviews; John Wiley \& Sons: Hoboken, NJ, USA, 2011; Volume 38, pp. 83-147, ISBN 9780470872376.

15. Council of the European Union. Council Regulation (EC) No 1234/2007 of 22 October 2007 establishing a common organisation of agricultural markets and on specific provisions for certain agricultural products (Single CMO Regulation). Off. J. Eur. Union 2007, 299, 1-149.

16. Baldo, M.A.; Oliveri, P.; Fabris, S.; Malegori, C.; Daniele, S. Fast determination of extra-virgin olive oil acidity by voltammetry and partial least squares regression. Anal. Chim. Acta 2019, 1056, 7-15. [CrossRef] [PubMed]

17. Peri, C. The Extra-Virgin Olive Oil Handbook, 1st ed.; Peri, C., Ed.; John Wiley \& Sons Ltd.: Hoboken, NJ, USA, 2014; ISBN 9781118460412.

18. Mariotti, M. Virgin olive oil: Definition. In The Extra-Virgin Olive Oil Handbook; Peri, C., Ed.; John Wiley \& Sons Ltd.: Hoboken, NJ, USA, 2014; pp. 11-19.

19. Bertuccioli, M.; Monteleone, E. The sensory quality of extra-virgin olive oil. In The Extra-Virgin Olive Oil Handbook; Peri, C., Ed.; John Wiley \& Sons Ltd.: Hoboken, NJ, USA, 2014; pp. 35-58.

20. Zanoni, B. The role of oxygen and water in the extra-virgin olive oil process Bruno. In The Extra-Virgin Olive Oil Handbook; Peri, C., Ed.; John Wiley \& Sons Ltd.: Hoboken, NJ, USA, 2014; pp. 69-74, ISBN 9781118460412.

21. Alamprese, C. Extra-virgin olive oil contaminants. In The Extra-Virgin Olive Oil Handbook; Peri, C., Ed.; John Wiley \& Sons Ltd.: Hoboken, NJ, USA, 2014; pp. 75-85, ISBN 9781118460412.

22. Marjani, A. Product and process certification. In The Extra-Virgin Olive Oil Handbook; Peri, C., Ed.; John Wiley \& Sons Ltd.: Hoboken, NJ, USA, 2014; pp. 251-261, ISBN 9781118460412.

23. Zanoni, B. Extra-virgin olive oil traceability. In The Extra-Virgin Olive Oil Handbook; Peri, C., Ed.; John Wiley \& Sons Ltd.: Hoboken, NJ, USA, 2014; pp. 245-250, ISBN 9781118460412.

24. Mariotti, M.; Peri, C. The composition and nutritional properties of extra-virgin olive oil. In The Extra-Virgin Olive Oil Handbook; Peri, C., Ed.; John Wiley \& Sons Ltd.: Hoboken, NJ, USA, 2014; pp. 21-34.

25. Sánchez-Villegas, A.; Sánchez-Tainta, A. Virgin olive oil. In The Prevention of Cardiovascular Disease through the Mediterranean Diet; Academic Press: Cambridge, MA, USA, 2018; pp. 59-87, ISBN 9780128112595.

26. Lombardo, L.; Grasso, F.; Lanciano, F.; Loria, S.; Monetti, E. Broad-Spectrum Health Protection of Extra Virgin Olive Oil Compounds, 1st ed.; Elsevier BV: Amsterdam, The Netherlands, 2018; Volume 57, ISBN 9780444640574.

27. Gavahian, M.; Mousavi Khaneghah, A.; Lorenzo, J.M.; Munekata, P.E.S.; Garcia-Mantrana, I.; Collado, M.C.; Meléndez-Martínez, A.J.; Barba, F.J. Health benefits of olive oil and its components: Impacts on gut microbiota antioxidant activities, and prevention of noncommunicable diseases. Trends Food Sci. Technol. 2019, 88, 220-227. [CrossRef]

28. Cicerale, S.; Lucas, L.J.; Keast, R.S.J. Antimicrobial, antioxidant and anti-inflammatory phenolic activities in extra virgin olive oil. Curr. Opin. Biotechnol. 2012, 23, 129-135. [CrossRef] [PubMed]

29. Piroddi, M.; Albini, A.; Fabiani, R.; Giovannelli, L.; Luceri, C.; Natella, F.; Rosignoli, P.; Rossi, T.; Taticchi, A.; Servili, M.; et al. Nutrigenomics of extra-virgin olive oil: A review. BioFactors 2017, 43, 17-41. [CrossRef] [PubMed]

30. Estruch, R.; Ros, E.; Salas-Salvadó, J.; Covas, M.-I.; Corella, D.; Arós, F.; Gómez-Gracia, E.; Ruiz-Gutiérrez, V.; Fiol, M.; Lapetra, J.; et al. Primary prevention of cardiovascular disease with a mediterranean diet supplemented with extra-virgin olive oil or nuts. N. Engl. J. Med. 2018, 378, 1-14. [CrossRef] [PubMed]

31. Storniolo, C.E.; Casillas, R.; Bulló, M.; Castañer, O.; Ros, E.; Sáez, G.T.; Toledo, E.; Estruch, R.; Ruiz-Gutiérrez, V.; Martínez-González, M.A.; et al. A Mediterranean diet supplemented with extra virgin olive oil or nuts improves endothelial markers involved in blood pressure control in hypertensive women. Eur. J. Nutr. 2017, 56, 89-97. [CrossRef]

32. Pintó, X.; Fanlo-Maresma, M.; Corbella, E.; Corbella, X.; Mitjavila, M.T.; Moreno, J.J.; Casas, R.; Estruch, R.; Corella, D.; Bulló, M.; et al. A Mediterranean diet rich in extra-virgin olive oil is associated with a reduced prevalence of nonalcoholic fatty liver disease in older individuals at high cardiovascular risk. J. Nutr. 2019, 149, 1920-1929. [CrossRef]

33. Mourouti, N.; Panagiotakos, D.B. The beneficial effect of a Mediterranean diet supplemented with extra virgin olive oil in the primary prevention of breast cancer among women at high cardiovascular risk in the PREDIMED Trial. Evid. Based Nurs. 2016, 19, 71. [CrossRef]

34. Frankel, E.N. Nutritional and biological properties of extra virgin olive oil. J. Agric. Food Chem. 2011, 59, 785-792. [CrossRef] 
35. International Olive Council. World Olive Encyclopaedia; International Olive Oil Council: Madrid, Spain, 1996; ISBN 9788401618819.

36. Rotondi, A.; Bendini, A.; Cerretani, L.; Mari, M.; Lercker, G.; Toschi, T.G. Effect of olive ripening degree on the oxidative stability and organoleptic properties of cv. Nostrana di Brisighella extra virgin olive oil. J. Agric. Food Chem. 2004, 52, 3649-3654. [CrossRef]

37. Sánchez, J.; Harwood, J.L. Biosynthesis of triacylglycerols and volatiles in olives. Eur. J. Lipid Sci. Technol. 2002, 104, 564-573. [CrossRef]

38. Servili, M.; Esposto, S.; Fabiani, R.; Urbani, S.; Taticchi, A.; Mariucci, F.; Selvaggini, R.; Montedoro, G.F. Phenolic compounds in olive oil: Antioxidant, health and organoleptic activities according to their chemical structure. Inflammopharmacology 2009, 17, 76-84. [CrossRef] [PubMed]

39. Echarte, M.M.; Puntel, L.A.; Aguirrezabal, L.A.N. Assessment of the critical period for the effect of intercepted solar radiation on sunflower oil fatty acid composition. F. Crop. Res. 2013, 149, 213-222. [CrossRef]

40. Molina-Garcia, L.; Santos, C.S.P.; Cunha, S.C.; Casal, S.; Fernandes, J.O. Comparative fingerprint changes of toxic volatiles in low PUFA vegetable oils under deep-frying. JAOCS J. Am. Oil Chem. Soc. 2017, 94, 271-284. [CrossRef]

41. Sun, Y.; Neelakantan, N.; Wu, Y.; Lote-oke, R.; Pan, A.; Dam, R.M. Van palm oil consumption increases LDL cholesterol compared with vegetable oils low in saturated fat in a meta-analysis of clinical. J. Nutr. Nutr. Epidemiol. 2015, 145, 1549-1558.

42. Criado, M.N.; Morelló, J.R.; Motilva, M.J.; Romero, M.P. Effect of growing area on pigment and phenolic fractions of virgin olive oils of the Arbequina variety in Spain. JAOCS J. Am. Oil Chem. Soc. 2004, 81, 633. [CrossRef]

43. Boskou, D.; Blekas, G.; Tsimidou, M. Olive Oil Composition, 2nd ed.; AOCS Press: Urbana, IL, USA, 2006; ISBN 9780128043547.

44. Conde, C.; Delrot, S.; Gerós, H. Physiological, biochemical and molecular changes occurring during olive development and ripening. J. Plant Physiol. 2008, 165, 1545-1562. [CrossRef]

45. Salvador, M.D.; Aranda, F.; Fregapane, G. Influence of fruit ripening on "Cornicabra" virgin olive oil quality: A study of four successive crop seasons. Food Chem. 2001, 73, 45-53. [CrossRef]

46. Roca, M.; Mínguez-Mosquera, M.I. Change in the natural ratio between chlorophylls and carotenoids in olive fruit during processing for virgin olive oil. JAOCS J. Am. Oil Chem. Soc. 2001, 78, 133-138. [CrossRef]

47. Kalogeropoulos, N.; Kaliora, A.C. Effect of Fruit Maturity on Olive Oil Phenolic Composition and Antioxidant Capacity; AOCS Press: Urbana, IL, USA, 2015; ISBN 9781630670429.

48. Caramia, G.; Gori, A.; Valli, E.; Cerretani, L. Virgin olive oil in preventive medicine: From legend to epigenetics. Eur. J. Lipid Sci. Technol. 2012, 114, 375-388. [CrossRef]

49. López-Miranda, J.; Pérez-Jiménez, F.; Ros, E.; De Caterina, R.; Badimón, L.; Covas, M.I.; Escrich, E.; Ordovás, J.M.; Soriguer, F.; Abiá, R.; et al. Olive oil and health: Summary of the II international conference on olive oil and health consensus report, Jaén and Córdoba (Spain) 2008. Nutr. Metab. Cardiovasc. Dis. 2010, 20, 284-294. [CrossRef]

50. Schwingshackl, L.; Hoffmann, G. Monounsaturated fatty acids and risk of cardiovascular disease: Synopsis of the evidence available from systematic reviews and meta-analyses. Nutrients 2012, 4, 1989. [CrossRef] [PubMed]

51. Borges, T.H.; Pereira, J.A.; Cabrera-Vique, C.; Lara, L.; Oliveira, A.F.; Seiquer, I. Characterization of Arbequina virgin olive oils produced in different regions of Brazil and Spain: Physicochemical properties, oxidative stability and fatty acid profile. Food Chem. 2017, 215, 454-462. [CrossRef] [PubMed]

52. Aranda, F.; Gómez-Alonso, S.; Rivera Del Álamo, R.M.; Salvador, M.D.; Fregapane, G. Triglyceride, total and 2-position fatty acid composition of Cornicabra virgin olive oil: Comparison with other Spanish cultivars. Food Chem. 2004, 86, 485-492. [CrossRef]

53. Alu, M.H.; Rababah, T.; Alhamad, M.N. Application of Olive Oil as Nutraceutical and Pharmaceutical Food: Composition and Biofunctional Constituents and Their Roles in Functionality, Therapeutic, and Nutraceutical Properties; Elsevier Inc.: Amsterdam, The Netherlands, 2017; ISBN 9780128114124.

54. Ambra, R.; Natella, F.; Lucchetti, S.; Forte, V.; Pastore, G. $\alpha$-Tocopherol, $\beta$-carotene, lutein, squalene and secoiridoids in seven monocultivar Italian extra-virgin olive oils. Int. J. Food Sci. Nutr. 2017, 68, 538-545. [CrossRef] 
55. Srigley, C.T.; Oles, C.J.; Kia, A.R.F.; Mossoba, M.M. Authenticity assessment of extra virgin olive oil: Evaluation of desmethylsterols and triterpene dialcohols. JAOCS J. Am. Oil Chem. Soc. 2016, 93, 171-181. [CrossRef]

56. Mapelli-Brahm, P.; Hernanz-Vila, D.; Stinco, C.M.; Heredia, F.J.; Meléndez-Martínez, A.J. Isoprenoids composition and colour to differentiate virgin olive oils from a specific mill. LWT Food Sci. Technol. 2018, 89, 18-23. [CrossRef]

57. Perrin, J.L. Minor components and natural antioxidants in olives and olive oil. Rev. Fr. Des Corps Gras 1992, 39, 25-32.

58. Moyano, M.J.; Meléndez-Martínez, A.J.; Alba, J.; Heredia, F.J. A comprehensive study on the colour of virgin olive oils and its relationship with their chlorophylls and carotenoids indexes (I): CIEXYZ non-uniform colour space. Food Res. Int. 2008, 41, 505-512. [CrossRef]

59. Grob, K.; Lanfranchi, M.; Mariani, C. Evaluation of olive oils through the fatty alcohols, the sterols and their esters by coupled LC-GC. J. Am. Oil Chem. Soc. 1990, 67, 626-634. [CrossRef]

60. Itoh, T.; Tamura, T.; Matsumoto, T. Methylsterol compositions of 19 vegetable oils. J. Am. Oil Chem. Soc. 1973, 50, 300-303. [CrossRef] [PubMed]

61. Boskou, D.; Morton, I.D. Changes in the sterol composition of olive oil on heating. J. Sci. Food Agric. 1975, 26, 1149-1153. [CrossRef]

62. Itoh, T.; Yoshida, K.; Yatsu, T.; Tamura, T.; Matsumoto, T.; Spencer, G.F. Triterpene alcohols and sterols of Spanish olive oil. J. Am. Oil Chem. Soc. 1981, 58, 545-550. [CrossRef]

63. Boarelli, M.C.; Biedermann, M.; Peier, M.; Fiorini, D.; Grob, K. Ergosterol as a marker for the use of degraded olives in the production of olive oil. Food Control 2020, 112, 107136. [CrossRef]

64. Gutiérrez, F.; Varona, I.; Albi, M.A. Relation of acidity and sensory quality with sterol content of olive oil from stored fruit. J. Agric. Food Chem. 2000, 48, 1106-1110. [CrossRef]

65. Ranalli, A.; Modesti, G.; Patumi, M.; Fontanazza, G. The compositional quality and sensory properties of virgin olive oil from a new olive cultivar-I-77. Food Chem. 2000, 69, 37-46. [CrossRef]

66. Rivera Del Álamo, R.M.; Fregapane, G.; Aranda, F.; Gómez-Alonso, S.; Salvador, M.D. Sterol and alcohol composition of Cornicabra virgin olive oil: The campesterol content exceeds the upper limit of $4 \%$ established by EU regulations. Food Chem. 2004, 84, 533-537. [CrossRef]

67. Chryssafidis, D.; Maggos, P.; Kiosseoglou, V.; Boskou, D. Composition of total and esterified $4 \alpha$-monomethylsterols and triterpene alcohols in virgin olive oil. J. Sci. Food Agric. 1992, 58, 581-583. [CrossRef]

68. Aparicio, R.; Luna, G. Characterisation of monovarietal virgin olive oils. Eur. J. Lipid Sci. Technol. 2002, 104, 614-627. [CrossRef]

69. Ranalli, A.; Ferrante, M.L.; De Mattia, G.; Costantini, N. Analytical evaluation of virgin olive oil of first and second extraction. J. Agric. Food Chem. 1999, 47, 417-424. [CrossRef]

70. Mariani, C. On the complexity of sterol fraction in olive oil|Sulla complessità della frazione sterolica nell'olio di oliva. Riv. Ital. Delle Sostanze Grasse 2016, 93, 147.

71. Rodrigues, N.; Casal, S.; Peres, A.M.; Baptista, P.; Bento, A.; Martín, H.; Asensio-S.-Manzanera, M.C.; Pereira, J.A. Effect of olive trees density on the quality and composition of olive oil from cv. Arbequina. Sci. Hortic. 2018, 238, 222-233. [CrossRef]

72. Grams, G.W.; Eskins, K. Dye-sensitized photooxidation of tocopherols. Correlation between singlet oxygen reactivity and vitamin E activity. Biochemistry 1972, 11, 606-608. [CrossRef] [PubMed]

73. Andrikopoulos, N.K.; Hassapidou, M.N.; Manoukas, A.G. The tocopherol content of greek olive oils. J. Sci. Food Agric. 1989, 46, 503-509. [CrossRef]

74. Rao, C.V.; Newmark, H.L.; Reddy, B.S. Chemopreventive effect of squalene on colon cancer. Carcinogenesis 1998, 19, 287-290. [CrossRef] [PubMed]

75. Smith, T.J.; Yang, G.Y.; Seril, D.N.; Liao, J.; Kim, S. Inhibition of 4-(methylnitrosamino)-1(3-pyridyl)-1-butanone-induced lung tumorigenesis by dietary olive oil and squalene. Carcinogenesis 1998, 19, 703-706. [CrossRef]

76. Lanzón, A.; Albi, T.; Cert, A.; Gracián, J. The hydrocarbon fraction of virgin olive oil and changes resulting from refining. J. Am. Oil Chem. Soc. 1994, 71, 285-291. [CrossRef] 
77. Sánchez de Medina, V.; Riachy, M.E.; Priego-Capote, F.; Luque de Castro, M.D. Mass spectrometry to evaluate the effect of the ripening process on phenols of virgin olive oils. Eur. J. Lipid Sci. Technol. 2013, 115, 1053-1061. [CrossRef]

78. Gimeno, E.; Castellote, A.I.; Lamuela-Raventós, R.M.; La Torre, M.C.D.; López-Sabater, M.C. The effects of harvest and extraction methods on the antioxidant content (phenolics, $\alpha$-tocopherol, and $\beta$-carotene) in virgin olive oil. Food Chem. 2002, 78, 207-211. [CrossRef]

79. Fito Colomer, M. Efectos Antioxidantes del Aceite de Oliva y de Sus Compuestos Fenólicos. Ph.D. Thesis, Universitat Autònoma de Barcelona, Bellaterra, Spain, 2003.

80. Cicerale, S.; Conlan, X.A.; Sinclair, A.J.; Keast, R.S.J. Chemistry and health of olive oil phenolics. Crit. Rev. Food Sci. Nutr. 2009, 49, 218-236. [CrossRef]

81. Boskou, D. Olive Oil: Minor Constituents and Health; CRC Press: Boca Raton, FL, USA, 2009; ISBN 9780367387143.

82. Covas, M.I.; Ruiz-Gutiérrez, V.; De La Torre, R.; Kafatos, A.; Lamuela-Raventós, R.M.; Osada, J.; Owen, R.W.; Visioli, F. Minor components of olive oil: Evidence to date of health benefits in humans. Nutr. Rev. 2006, 64, S20-S30. [CrossRef]

83. Konstantinidou, V.; Covas, M.; Muñoz-Aguayo, D.; Khymenets, O.; Torre, R.; Saez, G.; Carmen Tormos, M.; Toledo, E.; Marti, A.; Ruiz-Gutiérrez, V.; et al. In vivo nutrigenomic effects of virgin olive oil polyphenols within the frame of the Mediterranean diet: A randomized controlled trial. FASEB J. 2010, 24, 2546-2557. [CrossRef] [PubMed]

84. Tsimidou, M. Polyphenols and quality of virgin olive oil in retrospect. Ital. J. Food Sci. 1998, 10, 99-116.

85. Segura-Carretero, A.; Menéndez-Menéndez, J.; Fernández-Gutiérrez, A. Polyphenols in olive oil: The importance of phenolic compounds in the chemical composition of olive oil. In Olives and Olive Oil in Health and Disease Prevention; Academic Press: Cambridge, MA, USA, 2010; ISBN 9780123744203.

86. Morelló, J.R.; Vuorela, S.; Romero, M.P.; Motilva, M.J.; Heinonen, M. Antioxidant activity of olive pulp and olive oil phenolic compounds of the arbequina cultivar. J. Agric. Food Chem. 2005, 53, 2002-2008. [CrossRef]

87. Murkovic, M.; Lechner, S.; Pietzka, A.; Bratacos, M.; Katzogiannos, E. Analysis of minor components in olive oil. J. Biochem. Biophys. Methods 2004, 61, 155-160. [CrossRef] [PubMed]

88. Bendini, A.; Cerretani, L.; Carrasco-Pancorbo, A.; Gómez-Caravaca, A.M.; Segura-Carretero, A.; Fernández-Gutiérrez, A.; Lercker, G. Phenolic molecules in virgin olive oils: A survey of their sensory properties, health effects, antioxidant activity and analytical methods. An overview of the last decade. Molecules 2007, 12, 1679. [CrossRef] [PubMed]

89. Brenes, M.; García, A.; García, P.; Garrido, A. Rapid and complete extraction of phenols from olive oil and determination by means of a coulometric electrode array system. J. Agric. Food Chem. 2000, 48, 5178-5183. [CrossRef]

90. De La Torre-Carbot, K.; Jauregui, O.; Gimeno, E.; Castellote, A.I.; Lamuela-Raventós, R.M.; López-Sabater, M.C. Characterization and quantification of phenolic compounds in olive oils by solid-phase extraction, HPLC-DAD, and HPLC-MS/MS. J. Agric. Food Chem. 2005, 53, 4331-4340. [CrossRef]

91. Rovellini, P.; Cortesi, N. Liquid chromatography-mass spectrometry in the study of oleuropein and ligstroside aglycons in virgin olive oil: Aldehydic, dialdehydic forms and their oxidized products. Riv. Ital. Sostanze Grasse 2002, 79, 1-14.

92. Mateos, R.; Cert, A.; Carmen Pérez-Camino, M.; García, J.M. Evaluation of virgin olive oil bitterness by quantification of secoiridoid derivatives. JAOCS J. Am. Oil Chem. Soc. 2004, 81, 71-75. [CrossRef]

93. Bianco, A.; Coccioli, F.; Guiso, M.; Marra, C. The occurrence in olive oil of a new class of phenolic compounds: Hydroxy-isochromans. Food Chem. 2002, 77, 405-411. [CrossRef]

94. Gómez-Alonso, S.; Salvador, M.D.; Fregapane, G. Phenolic compounds profile of Cornicabra virgin olive oil. J. Agric. Food Chem. 2002, 50, 6812-6817. [CrossRef]

95. Montealegre, C.; Alegre, M.L.M.; García-Ruiz, C. Traceability markers to the botanical origin in olive oils. J. Agric. Food Chem. 2010, 58, 28-38. [CrossRef]

96. Lazzerini, C.; Cifelli, M.; Domenici, V. Pigments in extra-virgin olive oil: Authenticity and quality. In Products from Olive Tree; Books on Demand: McFarland, WI, USA, 2016.

97. Lazzerini, C.; Domenici, V. Pigments in extra-virgin olive oils produced in Tuscany (Italy) in different years. Foods 2017, 6, 25. [CrossRef] [PubMed] 
98. Uncu, O.; Ozen, B. Importance of some minor compounds in olive oil authenticity and quality. Trends Food Sci. Technol. 2020, 100, 164-176. [CrossRef]

99. Lazzerini, C.; Cifelli, M.; Domenici, V. Pigments in extra virgin olive oils produced in different mediterranean countries in 2014: Near UV-vis spectroscopy versus HPLC-DAD. LWT Food Sci. Technol. 2017, 84, 586-594. [CrossRef]

100. Gandul-Rojas, B.; Roca, M.; Gallardo-Guerrero, L. Chlorophylls and carotenoids in food products from olive tree. In Products from Olive Tree; Books on Demand: McFarland, WI, USA, 2016.

101. Tena, N.; Wang, S.C.; Aparicio-Ruiz, R.; García-González, D.L.; Aparicio, R. In-depth assessment of analytical methods for olive oil purity, safety, and quality characterization. J. Agric. Food Chem. 2015, 63, 4509-4526. [CrossRef] [PubMed]

102. Gandul-Rojas, B.; Cepero, M.R.L.; Mínguez-Mosquera, M.I. Use of chlorophyll and carotenoid pigment composition to determine authenticity of virgin olive oil. JAOCS J. Am. Oil Chem. Soc. 2000, 77, 853-858. [CrossRef]

103. Roca, M.; Gandul-Rojas, B.; Gallardo-Guerrero, L.; Mínguez-Mosquera, M.I. Pigment parameters determining spanish virgin olive oil authenticity: Stability during storage. JAOCS J. Am. Oil Chem. Soc. 2003, 80, 1237-1240. [CrossRef]

104. Aparicio-Ruiz, R.; Gandul-Rojas, B. Decoloration kinetics of chlorophylls and carotenoids in virgin olive oil by autoxidation. Food Res. Int. 2014, 65, 199-206. [CrossRef]

105. Giuliani, A.; Cerretani, L.; Cichelli, A. Chlorophylls in olive and in olive oil: Chemistry and occurrences. Crit. Rev. Food Sci. Nutr. 2011, 51, 678-690. [CrossRef] [PubMed]

106. Menotti, A.; Puddu, P.E. How the seven countries study contributed to the definition and development of the Mediterranean diet concept: A 50-year journey. Nutr. Metab. Cardiovasc. Dis. 2015, 25, 245-252. [CrossRef] [PubMed]

107. Martinez-Gonzalez, M.A.; Corella, D.; Salas-Salvado, J.; Ros, E.; Covas, M.I.; Fiol, M.; Warnberg, J.; Aros, F.; Ruiz-Gutierrez, V.; Lamuela-Raventos, R.M.; et al. Cohort profile: Design and methods of the PREDIMED study. Int. J. Epidemiol. 2012, 41, 377-385. [CrossRef]

108. Hernáez, Á.; Castañer, O.; Elosua, R.; Pintó, X.; Estruch, R.; Salas-Salvadó, J.; Corella, D.; Arós, F.; Serra-Majem, L.; Fiol, M.; et al. Mediterranean diet improves high-density lipoprotein function in high-cardiovascular-risk individuals. Circulation 2017, 135, 633-643. [CrossRef] [PubMed]

109. Hernáez, Á.; Castañer, O.; Goday, A.; Ros, E.; Pintó, X.; Estruch, R.; Salas-Salvadó, J.; Corella, D.; Arós, F.; Serra-Majem, L.; et al. The Mediterranean diet decreases LDL atherogenicity in high cardiovascular risk individuals: A randomized controlled trial. Mol. Nutr. Food Res. 2017, 61, 1601015. [CrossRef] [PubMed]

110. Toledo, E.; Salas-Salvadó, J.; Donat-Vargas, C.; Buil-Cosiales, P.; Estruch, R.; Ros, E.; Corella, D.; Fitó, M.; Hu, F.B.; Arós, F.; et al. Mediterranean diet and invasive breast cancer risk among women at high cardiovascular risk in the PREDIMED trial. JAMA Intern. Med. 2015, 175, 1752. [CrossRef]

111. Salas-Salvadó, J.; Bulló, M.; Estruch, R.; Ros, E.; Covas, M.-I.; Ibarrola-Jurado, N.; Corella, D.; Arós, F.; Gómez-Gracia, E.; Ruiz-Gutiérrez, V.; et al. Prevention of diabetes with mediterranean diets. Ann. Intern. Med. 2014, 160, 1-10. [CrossRef]

112. Guasch-Ferré, M.; Hu, F.B.; Martínez-González, M.A.; Fitó, M.; Bulló, M.; Estruch, R.; Ros, E.; Corella, D.; Recondo, J.; Gómez-Gracia, E.; et al. Olive oil intake and risk of cardiovascular disease and mortality in the PREDIMED Study. BMC Med. 2014, 12, 78. [CrossRef]

113. Zamora-Zamora, F.; Martínez-Galiano, J.M.; Gaforio, J.J.; Delgado-Rodríguez, M.; Delgado-Rodríguez, M. Effects of olive oil on blood pressure: A systematic review and meta-analysis. Grasas Aceites 2018, 69, 272. [CrossRef]

114. Martínez-González, M.A.; Dominguez, L.J.; Delgado-Rodríguez, M. Olive oil consumption and risk of CHD and/or stroke: A meta-analysis of case-control, cohort and intervention studies. Br. J. Nutr. 2014, 112, $248-259$. [CrossRef]

115. George, E.S.; Marshall, S.; Mayr, H.L.; Trakman, G.L.; Tatucu-Babet, O.A.; Lassemillante, A.C.M.; Bramley, A.; Reddy, A.J.; Forsyth, A.; Tierney, A.C.; et al. The effect of high-polyphenol extra virgin olive oil on cardiovascular risk factors: A systematic review and meta-analysis. Crit. Rev. Food Sci. Nutr. 2019, 59, 2772-2795. [CrossRef] [PubMed] 
116. EFSA. Panel on dietetic products nutrition and allergies (NDA) scientific opinion on the substantiation of health claims related to polyphenols in olive and protection of LDL particles from oxidative damage (ID 1333, $1638,1639,1696,2865)$, maintenance of normal blood HDL cholesterol concentrations (ID 1639), mainte. EFSA J. 2011, 9, 1-25.

117. Covas, M.-I.; de la Torre, K.; Farré-Albaladejo, M.; Kaikkonen, J.; Fitó, M.; López-Sabater, C.; Pujadas-Bastardes, M.A.; Joglar, J.; Weinbrenner, T.; Lamuela-Raventós, R.M.; et al. Postprandial LDL phenolic content and LDL oxidation are modulated by olive oil phenolic compounds in humans. Free Radic. Biol. Med. 2006, 40, 608-616. [CrossRef] [PubMed]

118. Fitó, M.; Cladellas, M.; de la Torre, R.; Martí, J.; Alcántara, M.; Pujadas-Bastardes, M.; Marrugat, J.; Bruguera, J.; López-Sabater, M.C.; Vila, J.; et al. Antioxidant effect of virgin olive oil in patients with stable coronary heart disease: A randomized, crossover, controlled, clinical trial. Atherosclerosis 2005, 181, 149-158. [CrossRef] [PubMed]

119. Hernáez, Á.; Remaley, A.T.; Farràs, M.; Fernández-Castillejo, S.; Subirana, I.; Schröder, H.; Fernández-Mampel, M.; Muñoz-Aguayo, D.; Sampson, M.; Solà, R.; et al. Olive oil polyphenols decrease LDL concentrations and LDL atherogenicity in men in a randomized controlled trial. J. Nutr. 2015, 145, 1692. [CrossRef] [PubMed]

120. Hohmann, C.D.; Cramer, H.; Michalsen, A.; Kessler, C.; Steckhan, N.; Choi, K.; Dobos, G. Effects of high phenolic olive oil on cardiovascular risk factors: A systematic review and meta-analysis. Phytomedicine 2015, 22, 631-640. [CrossRef] [PubMed]

121. López-Biedma, A.; Sánchez-Quesada, C.; Delgado-Rodríguez, M.; Gaforio, J.J. The biological activities of natural lignans from olives and virgin olive oils: A review. J. Funct. Foods 2016, 26, 36-47. [CrossRef]

122. Fernandes, J.; Fialho, M.; Santos, R.; Peixoto-Plácido, C.; Madeira, T.; Sousa-Santos, N.; Virgolino, A.; Santos, O.; Vaz Carneiro, A. Is olive oil good for you? A systematic review and meta-analysis on anti-inflammatory benefits from regular dietary intake. Nutrition 2020, 69, 110559. [CrossRef]

123. Schwingshackl, L.; Christoph, M.; Hoffmann, G. Effects of olive oil on markers of inflammation and endothelial function-A systematic review and meta-analysis. Nutrients 2015, 7, 5356. [CrossRef]

124. Camargo, A.; Rangel-Zuñiga, O.A.; Haro, C.; Meza-Miranda, E.R.; Peña-Orihuela, P.; Meneses, M.E.; Marin, C.; Yubero-Serrano, E.M.; Perez-Martinez, P.; Delgado-Lista, J.; et al. Olive oil phenolic compounds decrease the postprandial inflammatory response by reducing postprandial plasma lipopolysaccharide levels. Food Chem. 2014, 162, 161-171. [CrossRef]

125. Psaltopoulou, T.; Kosti, R.I.; Haidopoulos, D.; Dimopoulos, M.; Panagiotakos, D.B. Olive oil intake is inversely related to cancer prevalence: A systematic review and a meta-analysis of 13800 patients and 23340 controls in 19 observational studies. Lipids Health Dis. 2011, 10, 1-16. [CrossRef] [PubMed]

126. Van den Brandt, P.A.; Schulpen, M. Mediterranean diet adherence and risk of postmenopausal breast cancer: Results of a cohort study and meta-analysis. Int. J. Cancer 2017, 140, 2220-2231. [CrossRef] [PubMed]

127. Schwingshackl, L.; Schwedhelm, C.; Galbete, C.; Hoffmann, G. Adherence to Mediterranean diet and risk of cancer: An updated systematic review and meta-analysis. Nutrients 2017, 9, 1063. [CrossRef] [PubMed]

128. Menendez, J.A.; Vazquez-Martin, A.; Garcia-Villalba, R.; Carrasco-Pancorbo, A.; Oliveras-Ferraros, C.; Fernandez-Gutierrez, A.; Segura-Carretero, A. tabAnti-HER2 (erbB-2) oncogene effects of phenolic compounds directly isolated from commercial extra-virgin olive oil (EVOO). BMC Cancer 2008, 8, 377. [CrossRef]

129. Menendez, J.A.; Vazquez-Martin, A.; Oliveras-Ferraros, C.; Garcia-Villalba, R.; Carrasco-Pancorbo, A.; Fernandez-Gutierrez, A.; Segura-Carretero, A. Analyzing effects of extra-virgin olive polyphenols on breast cancer-associated fatty acid synthase protein expression using reverse-phase protein microarrays. Int. J. Mol. Med. 2008, 22, 433-439. [CrossRef]

130. Fini, L.; Hotchkiss, E.; Fogliano, V.; Graziani, G.; Romano, M.; De Vol, E.B.; Qin, H.; Selgrad, M.; Boland, C.R.; Ricciardiello, L. Chemopreventive properties of pinoresinol-rich olive oil involve a selective activation of the ATM-p53 cascade in colon cancer cell lines. Carcinogenesis 2008, 29, 139-146. [CrossRef]

131. Martín-Peláez, S.; Mosele, J.I.; Pizarro, N.; Farràs, M.; de la Torre, R.; Subirana, I.; Pérez-Cano, F.J.; Castañer, O.; Solà, R.; Fernandez-Castillejo, S.; et al. Effect of virgin olive oil and thyme phenolic compounds on blood lipid profile: Implications of human gut microbiota. Eur. J. Nutr. 2017, 56, 119-131. [CrossRef] 
132. Moorthy, M.; Chaiyakunapruk, N.; Jacob, S.A.; Palanisamy, U.D. Prebiotic potential of polyphenols, its effect on gut microbiota and anthropometric/clinical markers: A systematic review of randomised controlled trials. Trends Food Sci. Technol. 2020, 99, 634-649. [CrossRef]

133. Rosignoli, P.; Fuccelli, R.; Fabiani, R.; Servili, M.; Morozzi, G. Effect of olive oil phenols on the production of inflammatory mediators in freshly isolated human monocytes. J. Nutr. Biochem. 2013, 24, 1513-1519. [CrossRef]

134. Luque-Sierra, A.; Alvarez-Amor, L.; Kleemann, R.; Martín, F.; Varela, L.M. Extra-virgin olive oil with natural phenolic content exerts an anti-inflammatory effect in adipose tissue and attenuates the severity of atherosclerotic lesions in Ldlr-/-.Leiden mice. Mol. Nutr. Food Res. 2018, 62, 1800295. [CrossRef]

135. Limketkai, B.N.; Wolf, A.; Parian, A.M. Nutritional Interventions in the patient with inflammatory bowel disease. Gastroenterol. Clin. North Am. 2018, 47, 155-177. [CrossRef] [PubMed]

136. Cabré, E.; Domènech, E. Impact of environmental and dietary factors on the course of inflammatory bowel disease. World J. Gastroenterol. 2012, 18, 3814. [CrossRef] [PubMed]

137. Rosillo, M.A.; Sánchez-Hidalgo, M.; Sánchez-Fidalgo, S.; Aparicio-Soto, M.; Villegas, I.; Alarcón-de-la-Lastra, C. Dietary extra-virgin olive oil prevents inflammatory response and cartilage matrix degradation in murine collagen-induced arthritis. Eur. J. Nutr. 2016, 55, 315-325. [CrossRef] [PubMed]

138. Aparicio-Soto, M.; Sánchez-Hidalgo, M.; Cárdeno, A.; González-Benjumea, A.; Fernández-Bolaños, J.G.; Alarcón-de-la-Lastra, C. Dietary hydroxytyrosol and hydroxytyrosyl acetate supplementation prevent pristane-induced systemic lupus erythematous in mice. J. Funct. Foods 2017, 29, 84-92. [CrossRef]

139. Martín, R.; Carvalho-Tavares, J.; Hernández, M.; Arnés, M.; Ruiz-Gutiérrez, V.; Nieto, M.L. Beneficial actions of oleanolic acid in an experimental model of multiple sclerosis: A potential therapeutic role. Biochem. Pharm. 2010, 79, 198-208. [CrossRef]

140. Martín, R.; Hernández, M.; Córdova, C.; Nieto, M. Natural triterpenes modulate immune-inflammatory markers of experimental autoimmune encephalomyelitis: Therapeutic implications for multiple sclerosis. Br. J. Pharm. 2012, 166, 1708-1723. [CrossRef]

141. Klimova, B.; Novotný, M.; Kuca, K.; Valis, M. Effect of an extra-virgin olive oil intake on the delay of cognitive decline: Role of secoiridoid oleuropein? Neuropsychiatr. Dis. Treat. 2019, 15, 3033-3040. [CrossRef]

142. Trichopoulou, A.; Lagiou, P.; Kuper, H.; Trichopoulos, D. Cancer and Mediterranean dietary traditions. Cancer Epidemiol. Prev. Biomark. 2000, 9, 869-873.

143. Reboredo-Rodríguez, P.; González-Barreiro, C.; Cancho-Grande, B.; Forbes-Hernández, T.Y.; Gasparrini, M.; Afrin, S.; Cianciosi, D.; Carrasco-Pancorbo, A.; Simal-Gándara, J.; Giampieri, F.; et al. Characterization of phenolic extracts from Brava extra virgin olive oils and their cytotoxic effects on MCF-7 breast cancer cells. Food Chem. Toxicol. 2018, 119, 73-85. [CrossRef]

144. Nanda, N.; Mahmood, S.; Bhatia, A.; Mahmood, A.; Dhawan, D.K. Chemopreventive role of olive oil in colon carcinogenesis by targeting noncoding RNAs and methylation machinery. Int. J. Cancer 2019, 144, 1180-1194. [CrossRef]

145. Romani, A.; Ieri, F.; Urciuoli, S.; Noce, A.; Marrone, G.; Nediani, C.; Bernini, R. Health effects of phenolic compounds found in extra-virgin olive oil, by-products, and leaf of Olea europaea L. Nutrients 2019, 11, 1776. [CrossRef] [PubMed]

146. Lin, S.; Wang, Z.; Lam, K.L.; Zeng, S.; Tan, B.K.; Hu, J. Role of intestinal microecology in the regulation of energy metabolism by dietary polyphenols and their metabolites. Food Nutr. Res. 2019, 63, 1518. [CrossRef] [PubMed]

147. Ozdal, T.; Sela, D.A.; Xiao, J.; Boyacioglu, D.; Chen, F.; Capanoglu, E. The reciprocal interactions between polyphenols and gut microbiota and effects on bioaccessibility. Nutrients 2016, 8, 78. [CrossRef] [PubMed]

148. Borzì, A.M.; Biondi, A.; Basile, F.; Luca, S.; Vicari, E.S.D.; Vacante, M. Olive oil effects on colorectal cancer. Nutrients 2019, 11, 32. [CrossRef] [PubMed]

149. Mokkala, K.; Houttu, N.; Cansev, T.; Laitinen, K. Interactions of dietary fat with the gut microbiota: Evaluation of mechanisms and metabolic consequences. Clin. Nutr. 2020, 39, 994-1018. [CrossRef]

150. De Pablos, R.M.; Espinosa-Oliva, A.M.; Hornedo-Ortega, R.; Cano, M.; Arguelles, S. Hydroxytyrosol protects from aging process via AMPK and autophagy; a review of its effects on cancer, metabolic syndrome, osteoporosis, immune-mediated and neurodegenerative diseases. Pharm. Res. 2019, 143, 58-72. [CrossRef] 
151. Gorzynik-Debicka, M.; Przychodzen, P.; Cappello, F.; Kuban-Jankowska, A.; Marino Gammazza, A.; Knap, N.; Wozniak, M.; Gorska-Ponikowska, M. Potential health benefits of olive oil and plant polyphenols. Int. J. Mol. Sci. 2018, 19, 686. [CrossRef]

152. Farr, S.A.; Price, T.O.; Dominguez, L.J.; Motisi, A.; Saiano, F.; Niehoff, M.L.; Morley, J.E.; Banks, W.A.; Ercal, N.; Barbagallo, M. Extra virgin olive oil improves learning and memory in SAMP8 Mice. J. Alzheimer's Dis. 2012, 28, 81-92. [CrossRef]

153. Bertelli, M.; Kiani, A.K.; Paolacci, S.; Manara, E.; Kurti, D.; Dhuli, K.; Bushati, V.; Miertus, J.; Pangallo, D.; Baglivo, M.; et al. Hydroxytyrosol: A natural compound with promising pharmacological activities. J. Biotechnol. 2020, 309, 29-33. [CrossRef]

154. Aroca-Santos, R.; Lastra-Mejías, M.; Cancilla, J.C.; Torrecilla, J.S. Intelligent modelling to monitor the evolution of quality of extra virgin olive oil in simulated distribution conditions. Biosyst. Eng. 2018, 172, 49-56. [CrossRef]

155. Calabria, D.; Mirasoli, M.; Guardigli, M.; Simoni, P.; Zangheri, M.; Severi, P.; Caliceti, C.; Roda, A. Paper-based smartphone chemosensor for reflectometric on-site total polyphenols quantification in olive oil. Sens. Actuators B Chem. 2020, 305, 127522. [CrossRef]

156. Domenici, V.; Ancora, D.; Cifelli, M.; Serani, A.; Veracini, C.A.; Zandomeneghi, M. Extraction of pigment information from near-UV vis absorption spectra of extra virgin olive oils. J. Agric. Food Chem. 2014, 62, 9317-9325. [CrossRef] [PubMed]

157. Lerma-García, M.J.; Simó-Alfonso, E.F.; Chiavaro, E.; Bendini, A.; Lercker, G.; Cerretani, L. Study of chemical changes produced in virgin olive oils with different phenolic contents during an accelerated storage treatment. J. Agric. Food Chem. 2009, 57, 7834-7840. [CrossRef] [PubMed]

158. Nedic, V.; Despotovic, D.; Cvetanovic, S.; Despotovic, M.; Babic, S. Comparison of classical statistical methods and artificial neural network in traffic noise prediction. Environ. Impact Assess. Rev. 2014, 49, $24-30$. [CrossRef]

159. Meenu, M.; Cai, Q.; Xu, B. A critical review on analytical techniques to detect adulteration of extra virgin olive oil. Trends Food Sci. Technol. 2019, 91, 391-408. [CrossRef]

160. Mallamace, D.; Longo, S.; Corsaro, C. Proton NMR study of extra virgin olive oil with temperature: Freezing and melting kinetics. Phys. A Stat. Mech. Its Appl. 2018, 499, 20-27. [CrossRef]

161. Song, W.; Song, Z.; Vincent, J.; Wang, H.; Wang, Z. Quantification of extra virgin olive oil adulteration using smartphone videos. Talanta 2020, 216, 120920. [CrossRef]

162. Reboredo-Rodríguez, P.; González-Barreiro, C.; Cancho-Grande, B.; Simal-Gándara, J.; Trujillo, I. Genotypic and phenotypic identification of olive cultivars from north-western Spain and characterization of their extra virgin olive oils in terms of fatty acid composition and minor compounds. Sci. Hortic. 2018, 232, 269-279. [CrossRef]

163. Reboredo-Rodríguez, P.; González-Barreiro, C.; Cancho-Grande, B.; Simal-Gándara, J.; Trujillo, I. Corrigendum to "Genotypic and phenotypic identification of olive cultivars from north-western Spain and characterization of their extra virgin olive oils in terms of fatty acid composition and minor compounds" (Scientia Horticulturae (2018) 232 (269-279). Sci. Hortic. 2019, 108624. [CrossRef]

164. Bakhouche, A.; Lozano-Sánchez, J.; Ballus, C.A.; Martínez-García, M.; Velasco, M.G.; Govantes, Á.O.; Gallina-Toschi, T.; Fernández-Gutiérrez, A.; Segura-Carretero, A. Monitoring the moisture reduction and status of bioactive compounds in extra-virgin olive oil over the industrial filtration process. Food Control 2014, 40, 292-299. [CrossRef]

165. Reboredo-Rodríguez, P.; González-Barreiro, C.; Cancho-Grande, B.; Simal-Gándara, J. Improvements in the malaxation process to enhance the aroma quality of extra virgin olive oils. Food Chem. 2014, 158, 534-545. [CrossRef] [PubMed]

166. Esposto, S.; Taticchi, A.; Urbani, S.; Selvaggini, R.; Veneziani, G.; Di Maio, I.; Sordini, B.; Servili, M. Effect of light exposure on the quality of extra virgin olive oils according to their chemical composition. Food Chem. 2017, 229, 726-733. [CrossRef]

167. Navajas-Porras, B.; Pérez-Burillo, S.; Morales-Pérez, J.; Rufián-Henares, J.A.; Pastoriza, S. Relationship of quality parameters, antioxidant capacity and total phenolic content of EVOO with ripening state and olive variety. Food Chem. 2020, 325, 126926. [CrossRef] [PubMed] 
168. Reboredo-Rodríguez, P.; González-Barreiro, C.; Cancho-Grande, B.; Fregapane, G.; Salvador, M.D.; Simal-Gándara, J. Characterisation of extra virgin olive oils from Galician autochthonous varieties and their co-crushings with Arbequina and Picual cv. Food Chem. 2015, 176, 493-503. [CrossRef]

169. Pristouri, G.; Badeka, A.; Kontominas, M.G. Effect of packaging material headspace, oxygen and light transmission, temperature and storage time on quality characteristics of extra virgin olive oil. Food Control 2010, 21, 412-418. [CrossRef]

170. Trypidis, D.; García-González, D.L.; Lobo-Prieto, A.; Nenadis, N.; Tsimidou, M.Z.; Tena, N. Real time monitoring of the combined effect of chlorophyll content and light filtering packaging on virgin olive oil photo-stability using mesh cell-FTIR spectroscopy. Food Chem. 2019, 395, 90-100. [CrossRef] [PubMed]

171. Silva, S.F.; Anjos, C.A.R.; Cavalcanti, R.N.; Celeghini, R.M.D.S. Evaluation of extra virgin olive oil stability by artificial neural network. Food Chem. 2015, 179, 35-43. [CrossRef]

172. Rotich, V.; Al Riza, D.F.; Giametta, F.; Suzuki, T.; Ogawa, Y.; Kondo, N. Thermal oxidation assessment of Italian extra virgin olive oil using an UltraViolet (UV) induced fluorescence imaging system. Spectrochim. Acta Part A Mol. Biomol. Spectrosc. 2020, 237, 118373. [CrossRef]

173. Laddomada, B.; Colella, G.; Tufariello, M.; Durante, M.; Angiuli, M.; Salvetti, G.; Mita, G. Application of a simplified calorimetric assay for the evaluation of extra virgin olive oil quality. Food Res. Int. 2013, 54, 2062-2068. [CrossRef]

174. Veneziani, G.; Esposto, S.; Taticchi, A.; Urbani, S.; Selvaggini, R.; Di Maio, I.; Sordini, B.; Servili, M. Cooling treatment of olive paste during the oil processing: Impact on the yield and extra virgin olive oil quality. Food Chem. 2017, 221, 107-113. [CrossRef]

175. Esposto, S.; Selvaggini, R.; Taticchi, A.; Veneziani, G.; Sordini, B.; Servili, M. Quality evolution of extra-virgin olive oils according to their chemical composition during 22 months of storage under dark conditions. Food Chem. 2020, 311, 126044. [CrossRef] [PubMed]

176. Iqdiam, B.M.; Welt, B.A.; Goodrich-Schneider, R.; Sims, C.A.; Baker, G.L.; Marshall, M.R. Influence of headspace oxygen on quality and shelf life of extra virgin olive oil during storage. Food Packag. Shelf Life 2020, 23, 100433. [CrossRef]

177. Kontominas, M.G. Olive oil packaging: Recent developments. In Olives and Olive Oil as Functional Foods; John Wiley \& Sons: Hoboken, NJ, USA, 2017.

178. Abbadi, J.; Afaneh, I.; Ayyad, Z.; Al-Rimawi, F.; Sultan, W.; Kanaan, K. Evaluation of the effect of packaging materials and storage temperatures on quality degradation of extra virgin olive oil from olives grown in Palestine. Am. J. Food Sci. Technol. 2014, 2, 162-174. [CrossRef]

179. Lolis, A.; Badeka, A.V.; Kontominas, M.G. Effect of bag-in-box packaging material on quality characteristics of extra virgin olive oil stored under household and abuse temperature conditions. Food Packag. Shelf Life 2019, 21, 100368. [CrossRef]

180. Yu, J.; Gleize, B.; Zhang, L.; Caris-Veyrat, C.; Renard, C.M.G.C. Microwave heating of tomato puree in the presence of onion and EVOO: The effect on lycopene isomerization and transfer into oil. LWT 2019, 113, 108284. [CrossRef]

181. Collado-González, J.; Grosso, C.; Valentão, P.; Andrade, P.B.; Ferreres, F.; Durand, T.; Guy, A.; Galano, J.M.; Torrecillas, A.; Gil-Izquierdo, Á. Inhibition of $\alpha$-glucosidase and $\alpha$-amylase by Spanish extra virgin olive oils: The involvement of bioactive compounds other than oleuropein and hydroxytyrosol. Food Chem. 2017, 235, 298-307. [CrossRef]

182. Nikou, T.; Liaki, V.; Stathopoulos, P.; Sklirou, A.D.; Tsakiri, E.N.; Jakschitz, T.; Bonn, G.; Trougakos, I.P.; Halabalaki, M.; Skaltsounis, L.A. Comparison survey of EVOO polyphenols and exploration of healthy aging-promoting properties of oleocanthal and oleacein. Food Chem. Toxicol. 2019, 125, 403-412. [CrossRef]

183. Khalil, S.; Awad, A.; Elewa, Y. Antidotal impact of extra virgin olive oil against genotoxicity, cytotoxicity and immunotoxicity induced by hexavalent chromium in rat. Int. J. Vet. Sci. Med. 2013, 1, 65-73. [CrossRef]

184. Roselli, L.; Cicia, G.; Del Giudice, T.; Cavallo, C.; Vecchio, R.; Carfora, V.; Caso, D.; Sardaro, R.; Carlucci, D.; De Gennaro, B. Testing consumers' acceptance for an extra-virgin olive oil with a naturally increased content in polyphenols: The case of ultrasounds extraction. J. Funct. Foods 2020, 69, 103940. [CrossRef]

185. Hernández-Hernández, C.; Morales-Sillero, A.; Fernández-Prior, M.Á.; Fernández-Bolaños, J.; de la Aguilera-Herrera, M.P.; Rodríguez-Gutiérrez, G. Extra virgin olive oil jam enriched with cocoa bean husk extract rich in theobromine and phenols. LWT 2019, 111, 278-283. [CrossRef] 
186. Demisli, S.; Theochari, I.; Christodoulou, P.; Zervou, M.; Xenakis, A.; Papadimitriou, V. Structure, activity and dynamics of extra virgin olive oil-in-water nanoemulsions loaded with vitamin D3 and calcium citrate. J. Mol. Liq. 2020, 306, 112908. [CrossRef]

187. Vargas-Ramella, M.; Pateiro, M.; Barba, F.J.; Franco, D.; Campagnol, P.C.B.; Munekata, P.E.S.; Tomasevic, I.; Domínguez, R.; Lorenzo, J.M. Microencapsulation of healthier oils to enhance the physicochemical and nutritional properties of deer pâté. LWT 2020, 125, 109223. [CrossRef] 